\title{
MODELING SOFTWARE PIRACY PROTECTION: MONOPOLY VERSUS DUOPOLY
}

\author{
Krešimir Žigić \\ Jiří Střelický \\ Michael Kúnin
}
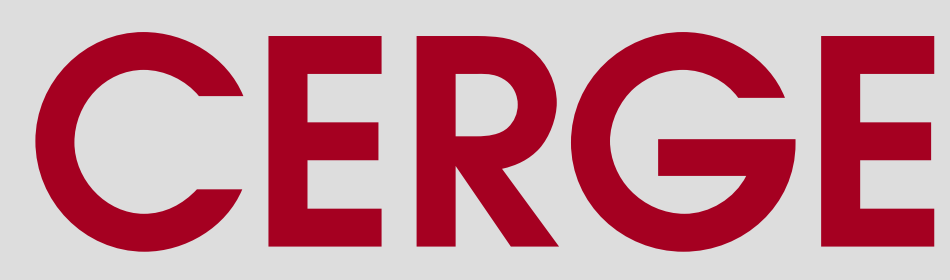


\title{
Working Paper Series (ISSN 1211-3298)
}

\section{Modeling Software Piracy Protection: Monopoly versus Duopoly}

\author{
Krešimir Žigić \\ Jiří Střelický \\ Michael Kúnin
}

CERGE-EI

Prague, October 2015 
ISBN 978-80-7343-358-1 (Univerzita Karlova v Praze, Centrum pro ekonomický výzkum a doktorské studium)

ISBN 978-80-7344-353-5 (Národohospodářský ústav AV ČR, v. v. i.) 


\title{
Modeling Software Piracy Protection: Monopoly versus Duopoly
}

\author{
Krešimir Žigić ${ }^{12}$, Jiří Střelický ${ }^{3}$, and Michael Kúnin ${ }^{4}$
}

\begin{abstract}
The economic analyses of software piracy typically rely on the simplifying assumption that the product is offered by a single producer. We argue that a realistic description of the software market and associated economic aspects of software piracy might be also captured by studying competition between software developers. Using an illegal version of software violates intellectual property rights (IPR) and, due to public protection (such as copyrights), is punishable when discovered. If a developer nonetheless considers the level of piracy to be high, he may introduce his own private protection. The focus of our analysis is on the interaction between public and private IPR protection in the two market structures under considerations. We show that, unlike in cases of monopolies, there is no conflict of interest between the regulator and producers in duopoly setup. Moreover, unlike in a monopoly, the optimal public IPR protection in duopoly does not affect the developers' choice of software quality.
\end{abstract}

Keywords: Software piracy, private and public IPR protection, quality and competition effects, vertically differentiated duopoly

JEL Classification: D43, L11, L21, O25, O34

\footnotetext{
${ }^{1}$ This project was financially supported by grant number P402/12/0961 from the Grant Agency of the Czech Republic. The authors would like to thank Martin Peitz, Paul Belleflamme, Milan Horniacek, Levent Celik, and Avner Shaked for their valuable comments on the first draft of the paper and to Volker Nocke, Benno Buehler, Jakub Kastl, Dragan Jovanović, Pierre Régibeau, John Sutton and the participants of the 8th CRESSE International conference on competition and regulation for their comments on the current version of the paper. The authors are grateful to O. Oryshchyn and B.Šokica for excellent technical assistance and A. Downing and D. Novakova for their superb English editing assistance.

${ }^{1}$ CERGE-EI, a joint workplace of the Center for Economic Research and Graduate Education, Charles University, and the Economics Institute of Academy of Sciences of the Czech Republic, Politických vězňů 7, Prague 1, 111 21, Czech Republic.

${ }^{2}$ kresimir.zigic@cerge-ei.cz, CERGE-EI

${ }^{3}$ CERGE-EI

${ }^{4}$ CERGE-EI
} 


\section{Introduction}

Most papers that deal with the positive and normative issues of software or digital piracy rely on the simplifying assumption that software is offered by a single producer because "...digital products within a given category are highly differentiated in the eyes of consumers... (see Belleflamme and Peitz, 2014. p.4). In other words, the cross-price elasticity is zero or "rather small", that is, the change of one product's price barely affects demand for the other products (see Belleflamme and Peitz, 2012 for a survey of such models). While this may be generally true in some cases, we argue that a realistic description of the software market might be also captured by studying competition among software developers. Typically there is a software product that is perceived as superior and priced much higher than its closest substitutes. Thus, if both the superior and inferior products are offered at the same price, all or most consumers would opt for the one that is considered of higher quality, or, in jargon, there is vertical product differentiation. In such a framework, for instance, one can figure out when the price of one product has no or minimal effect on the demand for the other product, and when the opposite is true, and when this is not the case. More specifically, this cross-price elasticity depends, among other things, on the perceived relation of software qualities between the products, captured by software quality ratio or its difference. Furthermore, the relationship between the qualities of legal software crucially determines which product(s), and under what circumstances, will become a target of software piracy. This, in turn determines overall consumers' ranking of software present in the market (note that pirated software might not necessarily be of the lowest perceived quality). For instance, in a market for vector graphic editing software, two relevant products are the Adobe Illustrator (included in the Adobe Creative Suite Design) and CorelDRAW (included in the CorelDRAW Graphic Suite). Adobe has a higher 
consumer rating and its price is 2.5 times higher than the Corel software, indicating that the products might be perceived as vertically differentiated ${ }^{5}$. Yet, cross price elasticity may not be negligible in this case and, consequently, both positive and normative aspects of piracy are likely to be different and more complex in case of competition between the firms. More generally, some of the interesting issues that occur in a duopoly setup either do not exist or cannot be fully addressed in a setup with only one developer.

The above insights motivate our paper, so we compare positive and, especially, normative issues of software piracy in a monopoly with an analogous duopoly setup. More specifically, we build simple models of software monopoly and duopoly and then investigate their respective optimal pricing, their optimal private IPR protection and, finally, the associated optimal public IPR protection (say, strength of copyright) in both setups. In particular, we are interested under which conditions and in which setup are the public and private IPR protections strategically complementary and when they act as strategic substitutes. We also study when there is (there is no) conflict of interest between the regulator and the developers.

For that purpose we put forward a dynamic three-stage model, where, in the last stage the monopolist sets the price (or two developers compete in prices for users with different price sensitivity). In the second stage of the game, the monopolist (or each developer in the case of duopoly) has an option to choose the level of its private IPR protection. Finally, in the first stage the government commits to a penalty for those users who are caught in their illegal use of software. That is, we rely on a quality competition model (see, for instance, Shaked and Sutton, 1984, and Tirole, 1988).

We concentrate on a particular and very simple practice of private IPR protection

\footnotetext{
${ }^{5}$ About the perceived quality of CorelDRAW, see http://www.softpedia.com/get/Multimedia/ Graphic/Graphic-Editors/ CorelDRAW-Graphics-Suite.shtml

and for Adobe Creative Suite Design, see http://www.softpedia.com/get/ Multimedia/Graphic/Graphic-Others/ Adobe-Creative-Suite-Design-Premium.shtml.
} 
that the developers use to protect their products. This practice appears in the form of decreasing product value (or degradation of product quality, in the language of Bae and Choi, 2006) to illegal users by denying various services related to the efficient use of software (say, by eliminating updates in antivirus or tune-up utilities, restricting access to users' manuals, etc.). We refer to this type of private protection as restricting services to illegal users.

The core of our analysis will be the interaction between the public (or government) and the private IPR protection in the two market structures under consideration. It is important to stress at the outset that (unlike the vast majority of papers that deal with IPR protection as the means to restore incentives to invest in $\mathrm{R} \& \mathrm{D}$ and product quality), we concentrate on the rather neglected aspect of short-run effects of IPR protection. That is, in most of our analysis we assume that the software qualities in question are given, so the role of IPR protection is not to incentivize investment in increased product qualities, but rather i) to enhance the presence of higher overall product quality in the market equilibrium by restraining or eliminating presence of pirated products (or in general, products with lower quality) and also ii) to increase the profits of legal developer(s). In other words, the role of the regulator is to balance these two effects by means of IPR protection in order to maximize social welfare. However, we extend our discussion on the long-run issues at the very end of our analysis and briefly discuss how the choice of qualities would affect our policy implications.

As for the empirical relevance of software end-users piracy, it is well documented in the vast body of literature dealing with digital piracy (see, for instance, Belleflamme and Peitz, 2012 for a comprehensive survey of the literature). The key contributing factors to violation of IPR and illegal imitations are the low costs and technical requirements required. In this light, the natural leaders in IPR violations are "information" products, (also known as digital content products), i.e. software, 
movies, music, and e-books. These products have two idiosyncratic attributes: imitations are often $100 \%$ identical to the original and the direct costs of copying are negligible. According to a report from the Business Software Alliance, the proportion of pirated software within the total software installed globally in 2008 climbed to $41 \%$ resulting in global losses in excess of $\$ 50$ billion. Even in the US, where the rate of illegal usage is the lowest, $20 \%$ of software is illegal, while in Western Europe the proportion is closer to one third. At the top of the list are Georgia, Pakistan, Indonesia, and China, where $80 \%$ and more of installed software is illegal.

The paper is structured as follows: following the literature survey, we present the set-up of our model in Section 3 and then, in Section 4 we analyze monopoly market structure that serves as a benchmark for a comparison with the duopoly outcome. We move on to the duopoly market interactions ${ }^{6}$ in Section 5 . We analyze the last stage of the game that deals with price competition among the developers and then briefly study how the change in private and public IPR protection affects equilibrium prices and profits. We continue with the second stage of the game which deals with the choice of the optimal private IPR protection. In Section 6, we focus on the key normative analysis of the optimal choice of public IPR protection in duopoly and its interaction with private IPR protection. In section 7 , we briefly discuss the implications and robustness of the results of the short-run analysis, when there is a choice of qualities in both setups. Finally, Section 8 is reserved for concluding remarks.

\footnotetext{
${ }^{6}$ Given our framework in which the high quality firm competes with the low quality firm, it seems that Stackelberg competition might be also an appropriate modeling approach. Střelický, J and Žigić, K, (2011), however, show that the Stackelberg setup does not bring any qualitatively new insight so we do not consider it here.
} 


\section{Survey of the Literature}

Most of the articles that deal with the issue of digital piracy and optimal public IPR protection rely on a monopoly set-up (see, for instance, Yoon, 2002, Banerjee, 2003; King and Lampe, 2003; Kúnin, 2004; Bae and Choi, 2006, Banerjee, et al., 2008. Takeyama, 2009, Ahn, and Shin, 2010). Our approach to the modelling of two kinds of IPR protection, private and public, is closest to that of Bae and Choi, 2006. They, however, do not make an explicit distinction between private and public IPR protection. Moreover, they offered an alternative explanation in which both types of protection can be interpreted as public IPR protection. As for the other monopoly papers, Banerjee (2003), for instance, demonstrates that the socially optimal level of IPR protection differs from a monopoly developer's optimum and stresses the role of network effects (NE). King and Lampe (2003) show that a monopoly allows illegal users in cases when the NE is present, while Takeyama (2009) shows that under asymmetric information about product quality, the copyright has to be imperfect in order to avoid adverse selection. Kúnin (2004) provides an explanation for why a software manufacturer may tolerate widespread copyright infringement in developing countries and often even offer local versions of their software. He showed that if NE are present and there is an expected improvement in copyright, then software manufacturers enter the market even if they incur losses in the beginning when copyright enforcement is weak. For a deeper and systematic review of the literature on the piracy of digital products, the interested reader is advised to look at the two excellent and comprehensive surveys in Peitz and Waelbroeck (2006) and Belleflamme and Peitz (2012).

As can be clearly seen from the Belleflamme and Peitz (2012) survey, there are indeed only a few articles which deal with the positive and normative issues of digital piracy while explicitly modeling direct competition between firms. Moreover, all of 
these papers, in general, rely on the notion of horizontal product differentiation (see the next section for a brief survey of the related literature). The pioneering article on this subject is that of Shy and Thisse (1999), who analyze piracy in the Hotelling-type duopoly competition where users have exogenous preferences for a particular developer ${ }^{7}$. They show that a developer's decision to introduce protection against illegal copying depends mainly on the NE, and that under strong NE, each developer decides not to implement protection in order to make his software more attractive and to increase their users base ${ }^{8}$. Jain (2008) builds upon the model of Shy and Thisse (1999) and assumes that firms can choose a level of IPR protection so that only a proportion of consumers with low product valuations can copy its product. They show that even in the absence of NE, firms may prefer weak copyright protection in equilibrium. Finally, Minnitti and Vergari (2010), also rely on the Hotelling differentiated-product duopoly framework but deal with a rather specific form of piracy similar to a private file sharing community and study how its presence affects the pricing behavior and profitability of producers of digital products.

The papers that are somewhat closer to the spirit of our analyses are the works of Belleflamme and Picard (2007) and Choi, Bae, and Jun (2010). These authors also study the interaction between public and private IPR protection in circumstances in which strategic interactions prevail. There are, however, several important differences in our approach. Firstly, we focus on direct strategic interaction between developers where two firms compete in prices in a vertically differentiated market, whereas the strategic interactions in Belleflamme and Picard (2007) and Choi, Bae, and Jun (2010) are indirect ones stemming from different copying technologies. Secondly, in addition to the different focus (direct versus indirect competition), the

\footnotetext{
${ }^{7}$ There is, however,a mistake in the article; see Peitz, (2004) for the correction of the mistake.

${ }^{8}$ We consider NEs unimportant in our setup and assume them away (see, however, Střelický and Žigić, 2011 for how NE could easily be incorporated in our set-up). Moreover, Poddar at al (2014) show that (contrary to the conventional wisdom) allowing piracy under the presence of strong NE is not profitable for a software developer when there are both private and public IPR protection.
} 
other key difference between our set-up and that of Belleflamme and Picard (2007) and Choi, Bae, and Jun (2010) is that in their settings the original products have the same quality, while in our set-up, the original products are vertically differentiated and thus have distinct qualities to begin with. Thirdly, since we focus on the software market, we do not allow for different copying technologies as is typically the case with multiple, initially independent digital products. Thus, the cost of consuming illegal copies is constant in our setting, while it may be decreasing with the number of different originals copied in the settings of Belleflamme and Picard (2007) and Choi, Bae, and Jun (2010). Last but not least, private IPR protection appears in the form of service restrictions in our approach while Belleflamme and Picard (2007) and Choi, Bae, and Jun (2010) assume rather standard Data Management Rights (DMR) protection.

\section{The Model}

\subsection{Industry set-up}

Even though the monopoly set up is the starting point of our analysis, it will be easily understood as the special case of a richer setup with two firms. So we first consider two developers, $A$ and $B$, who compete in prices on a particular market and offer product varieties of different quality. Developer $A$ releases a product of quality $q_{A}$, while the product quality offered by the second developer B is $q_{B}$ and we assume, without loss of generality, in the rest of the article that developer $A$ offers higher quality $\left(q_{A}>q_{B}\right)$. Product qualities $q_{A}, q_{B}$, are for the time being assumed to be exogenous and cannot be changed by developers ${ }^{9}$. We assume that both developers already exist before meeting and competing on the market under consideration and

\footnotetext{
${ }^{9}$ In section 7 , we will briefly comment on how the findings and conclusion of our short-run analysis would change if we allow developers to choose the qualities (see, for instance, Shaked and Sutton, 1982 and 1983; Kúnin and Žigić, 2006 for the modelling of quality choice).
} 
that both had already determined their respective qualities. Consequently, both developers are assumed to have already incurred fixed set-up costs and fixed costs associated with software development (R\&D costs). As these sunk costs do not enter in the economic optimization under consideration we have left them out of the profit function. With the qualities exogenously given, we can conceive our analysis as a short (or medium) run analysis as opposed to a long-run analysis in which firms choose the qualities (see Section 7). Finally, the unit variable costs are assumed to be constant and normalized to zero.

We further assume that developers cannot directly restrict illegal usage of the product itself but could restrict part of the services related to the product. This restriction lowers the product value for illegal users. That is, the value of the legal version differs from that of the illegal version since a developer provides some of his valuable services only to legal users (such as online help and technical support, live updates, a discount for upgrades and even free training, access to user manuals, etc.). Probably the most famous example of restricting services to illegal users, familiar to everybody, is that of Microsoft Windows. Microsoft's Windows Genuine Program allows a user to run an illegal version of the product only up to a certain point. In order to install selected patches/updates, the user has to validate the originality of the program online. If a particular copy is identified as illegal, some functions are disabled, and the illegal user is irritated with constant messages about buying the legal version. If a user decides not to validate the program online, he cannot update his Windows further for selected components (e.g. Windows Media Player or Internet Explorer $)^{10}$. The implementation of such a restriction is technically easy since the developer could use the standard tools that restrain access to those services

\footnotetext{
${ }^{10}$ Illegal versions of some antivirus software, e.g., Symantec Antivirus, might not update their installed databases of viruses and thus the $\mathrm{PC}$ is more vulnerable in the case of the latest virus attack. Similarly, tune-up utilities may not update their internal list of supported problems, so some new errors cannot be corrected. For other examples of decreasing product value, see Bae and Choi, 2006
} 
that require user authorization based on verification of personal information. In the case of automatic access to those services, a developer can use very reliable tools as authorization is based on the IP address or hard-locks.

If the value (perceived quality) of the legal version is $q_{i}$, then, the value of the product to illegal users decreases to $\alpha q_{i}$ so these users face "degradation costs" that are proportional to consumers' valuation of the original product (see Bae and Choi, 2006). The variable $\alpha \in(\underline{\alpha}, 1)$, and $\underline{\alpha}>0$ stands for technically the highest possible level of restriction (that is, the lowest possible $\alpha$ ) beyond which it is impossible to further restrain services ${ }^{11}$.

As for the developers' costs of restricting services, it seems reasonable to assume that these costs are negligible given that the developers already exist and have chosen their quality levels and the accompanying level of consumer services previously. So, we assume these costs to be zero, but we do discuss the implications of nonzero costs for the optimal choice of $\alpha$ in Appendix II.

An alternative way to conduct private IPR protection implies some kind of physical protection, or more generally, a so called DRM (Digital Rights Management) system ${ }^{12}$. The main drawback of the DRM system, however, is that it also imposes costs for legal users so that the quality of the original may be even lower than the quality of a copy. Moreover it often restricts the usage far beyond the copyright laws (e.g., not only against illegal copying, but even legal usage, such as restricting the use of a legally purchased e-book to only one device). DRM is thus considered a controversial and somewhat problematic approach to protecting IPR. For instance,

\footnotetext{
${ }^{11}$ Technically, the maximal possible private protection $(\alpha=\underline{\alpha})$ is the one at which quality $q_{A}$ to legal users is still not adversely affected. Decreasing $\alpha$ below $\underline{\alpha}$ would require such strong protection/verification tools (e.g. manual online authorization), that it would become annoying even for legal users resulting in quality drop below $q_{A}$.

${ }^{12} \mathrm{DRM}$ is an umbrella term for various technologies that may limit the usage of digital content in ways unintended by the developer. Most major content providers such as Microsoft, Sony, Amazon, or Apple used to exploit DRM. Nowadays most content providers experiment with DRMfree alternatives, mainly in music (see more on DRM in Belleflamme and Peitz, 2010 and also Scotchmer, 2004). See also Sundararajan, 2004 for an analysis of optimal technological protection and pricing when a firm uses DRM.
} 
Belleflamme and Peitz, 2012 note that "...recent development in digital distribution suggest that DRM is on a losing path since not only Apple but also Amazon and Walmart have started selling DRM-free digital music". The remarkable difference between DRM and private protection in the form of service restrictions is that the latter typically does not impose any costs on the developers on one hand, while also not adversely affecting the utility of the legal users on the other (see Zhang, 2013 for the empirical analysis on these two conflicting effects).

\subsection{The regulator's role}

The regulator chooses the level of punishment and the monitoring efforts in order to maximize social welfare (that is, the sum of profits, consumer surplus and revenue collected from the penalty net of the monitoring costs - see section 6 for the precise definition). More specifically, the regulator has the expected penalty $X$ under its control that is defined as the product of the size of penalty and the commonly perceived probability by both the developers and consumers that an infringer would be caught, where the perceived probability is assumed to be the same for all consumers and developers. In a sense, $X$ can be interpreted as the piracy costs that include the risks and inconveniences that consumers bear when making copies (see Ahn, I., Shin, I. 2010). Like most of the literature, we assume that the government's punishment, $X$, (or public protection) is broad-based in the sense that it raises the piracy costs to all consumers ${ }^{13}$.

As for the monitoring costs, $C(X)$, it is reasonable to assume that they are convex so we assume that $C(0)=C^{\prime}(0)=0, C^{\prime}(X)>0$ and $C^{\prime \prime}(X)>0$. Finally, there is empirical evidence that copyright software protection adversely affects software piracy (see Andres, 2006).

\footnotetext{
${ }^{13}$ However, there is also an alternative approach in which public protection mostly targets institutional and corporate users rather than individual users. See Harbaugh and Khemka, 2010 and the relevant literature cited there on such an approach.
} 


\subsection{Users set-up}

The users (consumers) differ in their quality sensitivity $\theta$, which has density 1 on $[0, \bar{\theta}]$. We assume that every user has access to all the versions: to both legal versions $A, B$ and to the illegal versions of $A, B$ and decides based on the product prices and values. Utility for a user $\theta$ is then:

$$
U_{P}(\theta)=\left\{\begin{array}{lll}
\theta q_{i}-p_{i} & \ldots & \text { if he buys software. } \\
\theta \alpha q_{i}-X & \ldots & \text { if he uses software illegally. } \\
0 & \ldots & \text { if he does not use software at all. }
\end{array}\right.
$$

There are always some users (top-end users with high $\theta$ ) that prefer to buy the legal version rather than the restricted illegal one even if both versions (legal and illegal) are available and even when $X$ goes to zero. It is also immediately clear that all users strictly prefer the illegal version of $A$ to the illegal version of $B$ (except $\theta=0$, who prefers using nothing). We denote $\theta_{Y Z}$ the quality sensitivity of the user indifferent between $Y$ and $Z$, where $Y, Z \in\{0, P, A, B\}$ ( $P$ is the illegal version of $A)$.

\subsection{The public and private IPR protection and the market structure}

Before proceeding to the analysis of the underlying three-stage games, it is instructive i) to see briefly how the two forms of IPR protection may interact and affect the market structure and market coverage and ii) to preliminarily introduce the market structures that we focus on. These market structures are monopoly and duopoly, in which three versions of the product (one illegal and two legal) are present in the market equilibrium. If only public protection is available, it is clear that the expected penalty $X$, when high enough, would completely protect the developers from 
piracy and result in a pure monopoly or standard Bertrand competition, making private IPR protection redundant. In the case of medium expected penalty in a monopoly where $X$ is lower than the pure monopoly price, a monopolist can either set the price to $X$ or not be active in the market. Similarly, in the case of duopoly and the medium expected penalty (where $X$ is lower than the optimal Bertrand price of developer $A$ ), developer $A$ may either not be active in the market or would have to decrease the price of the product. In such a market situation, $X$ fosters competition and forces both developers to decrease prices, but at the same time, too low an $X$ could squeeze one of the developers out of the market since he may no longer be able to compete. From the government's point of view, $X$ serves as an artificial price that must either be accepted by developer $A$, or he has to be inactive in that market. In the case of a very low $X$ (where $X$ is now lower than the optimal Bertrand price of developer $B$ ), none of the developers would operate in the market ${ }^{14}$. Note that in the absence of private IPR protection, the users do not perceive a quality (value) difference between the original product and its illegal version, and thus, users always choose the version with a lower "cost" per quality unit $\left(\frac{p_{i}}{q_{i}}\right.$ in the case of a legal version and $\frac{X}{q i}$ in the case of an illegal version).

When, on the other hand, private IPR protection is present as well, the legal and illegal versions are not perfect substitutes. That is, the value of the legal version for a user $\theta$ is $\theta q_{i}$ and $\theta q_{i}>\alpha \theta q_{i}$ due to the services restriction for illegal usage. Now there will always be legal users and at least one developer present in the market under consideration even if public IPR is absent. The reason is that there are always users with high $\theta$ that prefer to buy the legal version rather than the illegal one. More specifically, if $q_{A}>\alpha q_{A}>q_{B}$ then the absence of public IPR protection would result in a monopoly by developer $A$, since he would sell the legal version of software to the top users while the end tail of the market will be comprised of pirate

\footnotetext{
${ }^{14}$ See Střelický, J and Žigić, K, 2011 for a detailed analysis of IPR protection in the absence of private IPR protection.
} 
users where a user $\theta$ of the product $A$ obtains (gross) utility of $\alpha \theta q_{A}$. Product $B$ will not be in the market. If, however, there is even a very small level of public IPR protection, then all three versions will again be present in the market, since developer $B$ could set the price $p_{B}<X$ given our assumption of zero marginal production costs and absence of entry sunk costs. This is the first of the two market structures in which both firms are active in equilibrium (we label it Case 1 or piracy duopoly, p1). In this case, however, the cross-price elasticity is zero, since, as we will see, there is a buffer of illegal users positioned between the two groups of legal users (see Figure 2). The relevant insights of this setup are rather close to those from monopoly market structure (see Žigić et al. 2013).

If, on the other hand, consumers value both legal versions more than the value of the illegal version (that is, $q_{A}>q_{B}>\alpha q_{A}$ ), then both developers would introduce IPR protection and be present in the market even if public protection is absent. So again all three versions of the product (that is, $q_{A}, q_{B}$ and $\alpha q_{A}$ ) will be in the market (despite that fact that the "cost" per quality unit would be such that $\frac{X}{\alpha q_{A}} \leq$ $\left.\frac{p_{B}}{q_{B}} \leq \frac{p_{A}}{q_{A}}\right)$. We label this market situation as Case 2 or piracy duopoly $(p \mathscr{2})$ and we argue that this setup is both more realistic and more relevant for comparison with monopoly outcome.

In what follows, we solve the game backwards for each market structure under considerations. We start with the optimal pricing in monopoly and then with the duopoly setup in which the two firms directly compete (Case 2). We analyze the impact of different $\alpha$ and $X$ on equilibrium prices and on the resulting market coverage. We then proceed with the second stage of the game in which the firm(s) choose(s) private protection, that is, the degree of service restrictions, and conclude with analysis and comparison of the government's choice of public protection in monopoly and duopoly. Finally, we briefly analyze the interaction between the two types of IPR protections in the two setups. 


\section{Monopoly}

We start with the monopoly case (of developer $A$ ). In this case, developer $A$ can compete only with an illegal version of his own product. If the expected penalty $X$ is high enough that nobody is willing to use illegal software, we obtain a pure monopoly. This situation occurs when $\frac{1}{2} \bar{\theta} \alpha q_{A} \leq X$.

In the case where $X \leq \frac{1}{2} \bar{\theta} \alpha q_{A}$, there are users who prefer to use the illegal version and so setting $\alpha$ as low as possible is the right thing to do in order to increase the demand for the legal version. In order to work out the monopolist's demand, we find user $\theta_{P A}$, who is indifferent between the legal and illegal product, and so this user is described by $\theta_{P A}=\frac{p_{M}-X}{q_{A}-\alpha q_{A}}$. The demand for product $A$ is then $D_{A}=\left(\bar{\theta}-\theta_{P A}\right)$, and the monopolist profit is $\pi_{M}=\left(\bar{\theta}-\theta_{P A}\right) p_{M}$, while the demand for the illegal version is $D_{P}=\left(\theta_{P A}-\theta_{0 P}\right)$. Equilibrium price and profit are:

$$
p_{M}^{*}=\frac{X+\bar{\theta} q_{A}(1-\alpha)}{2}, \pi_{M}^{*}=\frac{1}{4} \frac{\left(X+\bar{\theta} q_{A}(1-\alpha)\right)^{2}}{q_{A}(1-\alpha)} .
$$

This results in the distribution of users on the market as captured in Figure 1.

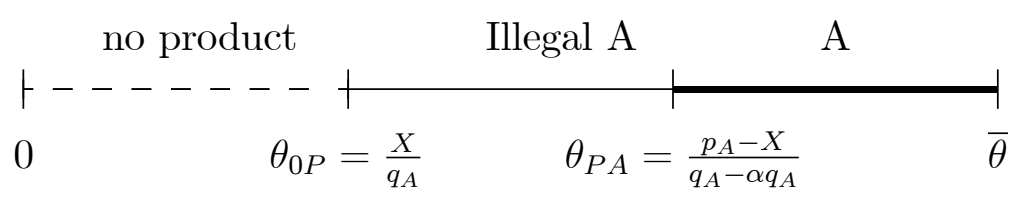

Figure 1: The decreased quality to illegal users on the monopoly market

Note that the monopolist who faces illegal usage, but has an option to increase the number of legal users by restricting additional services, generates uniformly higher profit than the monopolist who could only set $p_{M}^{*}=X$. 


\section{Duopoly}

\subsection{The last stage - competition in prices}

We use the notion of subgame perfect Nash equilibrium as the solution concept. Note that a user's decision to use an illegal version depends on the user's sensitivity to product quality $\theta$ as well as on the expected penalty $X$ and the service restriction $\alpha$. If $X$ is high enough such that in equilibrium $p_{B}<p_{A}<X$, then illegal usage is fully suppressed, the private IPR protection is redundant and the market is divided between both developers ${ }^{15}$. If the illegal usage is not eliminated, and legal versions are on the market, then, as we know, there are two cases in which both developers operate on the market: Case 1 when $q_{B}<\alpha q_{A}$ (implying that in equilibrium $\frac{p_{B}}{q_{B}} \leq$ $\frac{X}{\alpha q_{A}} \leq \frac{p_{A}}{q_{A}}$ ), and Case 2 when $\alpha q_{A}<q_{B}$ (implying that in equilibrium $\frac{X}{\alpha q_{A}} \leq \frac{p_{B}}{q_{B}} \leq \frac{p_{A}}{q_{A}}$ ). In all other cases, either the legal version of product $B$ is eliminated so that developer $A$ has a monopoly, or the illegal usage of product $A$ is eliminated and there is a pure or constrained (non-piracy) duopoly (see Graph 1) ${ }^{16}$.

Case 1 is similar to the setup in which a monopolist competes with its illegal version $^{17}$ (see Figure 2 ). In Case 2, however, two developers compete directly with each other (see Figure 3). Moreover, when $X$ is zero or "low," and $A$ introduces strict restrictions on his services (such that $\alpha q_{A}<q_{B}$ ), developer $B$ has to introduce protection as well because no user would use product $B$ legally unless developer $B$ also protects his software (see Case 2 below).

The above facts indicate that there are some distinctive features between competition in monopoly vis-a-vis duopoly competition in Case 2, (direct competition

\footnotetext{
${ }^{15}$ In this part, whenever we write $p_{B}<p_{A}$ we mean $\frac{p_{B}}{q_{B}}<\frac{p_{A}}{q_{A}}$, which is a necessary condition for product $B$ to be in the market.

${ }^{16}$ Supplementary Material containing the complete analysis of the last stage of the game and all price equilibria can be found on Michael Kúnin's home page: http://home.cerge-ei.cz/kunin/ or can be obtained from the authors upon request.

${ }^{17}$ Both firm's A price and profit are identical to the corresponding values in monopoly (see Zigic et al, 2013).
} 
between developers, both firms implement private IPR protection, etc.). Thus we focus on Case 2 in our analysis and our comparison of piracy effects in duopoly and monopoly.

$$
\begin{aligned}
& \text { B } \\
& 0
\end{aligned} \quad \begin{gathered}
\text { Illegal A } \\
\theta_{B 0}=\frac{p_{B}}{q_{B}} \quad \theta_{B P}=\frac{X-p_{B}}{\alpha q_{A}-q_{B}} \quad \theta_{P A}=\frac{p_{A}-X}{q_{A}-\alpha q_{A}} \quad \bar{\theta}
\end{gathered}
$$

Figure 2: BC with illegal users in the middle of the market

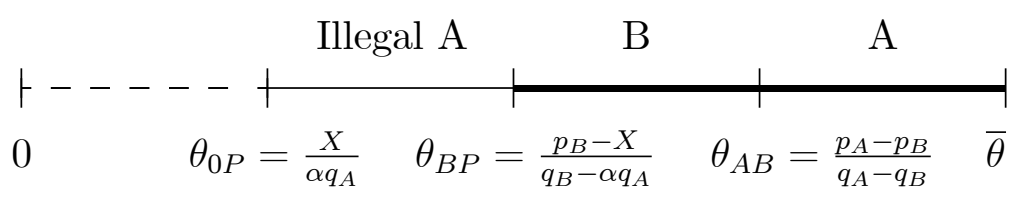

Figure 3: $\mathrm{BC}$ with illegal users at the low end of the market

\subsection{Piracy duopoly when $q_{B}>\alpha q_{A}$}

Given that Case 1 does not bring significantly different insights than monopoly, we immediately turn to Case 2. Note that in this set-up, developer $B$ would also be forced to introduce the IPR protection of, say $\alpha_{B}$, in order to stay in the market. Otherwise the users who do not buy a legal version of product $A$ would prefer to use the illegal version of product $B$, whose quality would be $q_{B}>\alpha q_{A}$. As a consequence of IPR implementation by both developers, there would be direct competition between the two developers, but their payoffs depend on the level of $X$ and the developer's $A$ IPR protection ${ }^{18}, \alpha$. A user indifferent between $A$ and $B$ is $\theta_{B A}=\frac{p_{A}-p_{B}}{q_{A}-q_{B}}$, and a user indifferent between illegal usage of $A$ and buying $B$ is

\footnotetext{
${ }^{18} \mathrm{We}$ assume that $\alpha_{B} q_{B}<\alpha q_{A}$. It is straightforward to figure out the outcome when the opposite is true but it brings no new insights.
} 
$\theta_{P B}=\frac{p_{B}-X}{q_{B}-\alpha q_{A}}$. Users with $\theta \in\left(\frac{X}{\alpha q_{A}}, \frac{p_{B}-X}{q_{B}-\alpha q_{A}}\right)$ use an illegal version of product $A$. The profits for developers are: $\pi_{A}=\left(\bar{\theta}-\theta_{B A}\right) p_{A}$ and $\pi_{B}=\left(\theta_{B A}-\theta_{P B}\right) p_{B}$.

This results in the following equilibrium prices and profits:

$$
p_{A}^{*}=\left(q_{A}-q_{B}\right) \frac{\bar{\theta} 2 q_{A}(1-\alpha)+X}{4 q_{A}-3 \alpha q_{A}-q_{B}}, p_{B}^{*}=\left(q_{A}-q_{B}\right) \frac{\bar{\theta}\left(q_{B}-\alpha q_{A}\right)+2 X}{4 q_{A}-3 \alpha q_{A}-q_{B}} .
$$

$$
\begin{aligned}
& \pi_{A}^{*}=\left(q_{A}-q_{B}\right)\left(\frac{2 \bar{\theta} q_{A}(1-\alpha)+X}{4 q_{A}-3 \alpha q_{A}-q_{B}}\right)^{2} \\
& \pi_{B}^{*}=\left(q_{A}-q_{B}\right)(1-\alpha) q_{A} \frac{\left(\bar{\theta}\left(q_{B}-\alpha q_{A}\right)+2 X\right)^{2}}{\left(q_{B}-\alpha q_{A}\right)\left(4 q_{A}-3 \alpha q_{A}-q_{B}\right)^{2}} .
\end{aligned}
$$

Note that in the equilibrium, we have $\frac{X}{\alpha q_{A}} \leq \frac{p_{B}}{q_{B}} \leq \frac{p_{A}}{q_{A}}$ implying that $X<p_{B}^{*}<p_{A}^{*}$.

Lemma 1 A necessary and sufficient condition for the existence of piracy equilibrium (p2) is satisfied only for $X$ and $\alpha$ such that:

$$
0 \leq X<X_{\alpha 2}=\frac{\bar{\theta}\left(q_{A}-q_{B}\right)\left(q_{B}-\alpha q_{A}\right) \alpha q_{A}}{4 q_{A} q_{B}-q_{B}^{2}-2 \alpha q_{A}^{2}-\alpha q_{A} q_{B}}
$$

\section{Proof. See Supplementary Material.}

Lemma 2 The equilibrium profit and price of developer $A$ as well as developer $B$ are decreasing in $\alpha$ when $q_{B}>\alpha q_{A}$ holds.

Recall that the competition in Case 2 is tougher than in Case 1 since developers now compete directly with each other, and the increase in market share of one developer automatically implies a decline in the share of the other developer. Again it is straightforward to show that the developers' profit increases in $X$ at the relevant range $0<X<X_{\alpha 2}$. 
Unlike in the case of monopoly (or Case 1), the cross price elasticities of firms $A$ and $B$ are not zero and they are respectively given as $\eta_{A B}$ and $\eta_{B A}$ below:

$$
\eta_{A B}=\frac{2 X+\bar{\theta}\left(q_{B}-\alpha q_{A}\right)}{X+2 \bar{\theta}(1-\alpha) q_{A}}
$$

and

$$
\eta_{B A}=2+\frac{X\left(q_{B}-q_{A}(4-3 \alpha)\right)}{q_{A}(1-\alpha)\left(2 X+\bar{\theta}\left(q_{B}-\alpha q_{A}\right)\right)} .
$$

Moreover, note that $\eta_{A B}<\eta_{B A}$ but an increase in $X$ raises $\eta_{A B}$ while $\eta_{B A}$ decreases in $X$, so a stricter public IPR protection makes competition tougher for firm $A$ and softer for firm $B$. In other words, firm $B$ benefits more from public protection than firm $A$. The reason for this is that raising public protection from, say, zero to some positive value of $X$ (such that $X<X_{\alpha 2}$ ) has a direct positive effect on developer $B$ since he is the one that directly competes with the illegal users. Increased public protection enables firm $B$ to capture some illegal users who now find the purchase of the legal version of firm $B$ more beneficial than the illegal use of software $A$. This, consequently, increases the lower (left) tail of developer's $B$ market enabling him to raise both his price and his profit. An increase in firm B's price shifts, in turn, the marginal consumer of the high quality good to the left enlarging thus developer's $A$ market coverage, and also enabling him to increase his price (even though at lower rate than price $B$ ) and, consequently his profit.

Finally, note that, unlike the increase in public IPR protection, an increase in private IPR protection predictably decreases the value of both $\eta_{A B}$ and $\eta_{B A}$ and thus softens the competition between the firms. 


\subsection{Non-piracy duopoly equilibria}

If $X$ exceeds the applicable threshold $X_{\alpha 2}$, then it turns out that the illegal product has zero market share in equilibrium, and two situations are possible.

- Constrained Non-piracy Duopoly (d2)): $D_{P}=0$ but the developers' prices depend on $X$.

- Unconstrained Non-piracy $\operatorname{Duopoly}(\boldsymbol{D}): D_{P}=0$, and the developers' prices do not depend on $X$ and are the same as under the classical Bertrand competition (see Graph 1):

$$
p_{A}=\frac{2 \bar{\theta} q_{A}\left(q_{A}-q_{B}\right)}{4 q_{A}-q_{B}}, \quad p_{B}=\frac{\bar{\theta} q_{B}\left(q_{A}-q_{B}\right)}{4 q_{A}-q_{B}} .
$$

It can be shown that unconstrained non-piracy equilibria occur in Case 2 for

$$
X>X_{\alpha 2+}=\frac{\bar{\theta}\left(q_{A}-q_{B}\right) \alpha q_{A}}{4 q_{A}-q_{B}}
$$

and that the intermediate values of $X$ lead to constrained non-piracy equilibria. In case 2 (see the area $\mathrm{d} 2$ in Graph 1 ), such equilibria are characterized by

$$
p_{A}=\frac{1}{2}\left(X \frac{q_{B}}{\alpha q_{A}}+\bar{\theta}\left(q_{A}-q_{B}\right)\right), \quad p_{B}=X \frac{q_{B}}{\alpha q_{A}} .
$$

Even though our main focus is on Case 2 as far as duopoly is concerned, we would also need the relevant thresholds $X_{\alpha 1}$ and $X_{\alpha 1+}$ for Case 1 in order to make the comparative analysis complete (as we will soon see). Thus, the necessary and sufficient condition with respect to $X$ for Case 1, or piracy equilibrium (p1) to exist is

$$
0<X<X_{\alpha 1}=\frac{\bar{\theta} \alpha q_{A}\left(\alpha q_{A}-q_{B}\right)(1-\alpha)}{(2-\alpha) \alpha q_{A}-q_{B}} .
$$


Finally, it can be shown that unconstrained non-piracy equilibria occur in case 1 for

$$
X>X_{\alpha 1+}=\frac{\bar{\theta}\left(2 \alpha q_{A}-(1+\alpha) q_{B}\right) q_{A}}{4 q_{A}-q_{B}}
$$

\subsection{The interaction between the public and private IPR pro- tection - the first look}

Even though both private $(\alpha)$ and public $(X)$ IPR protections are endogenously (and optimally) determined in the previous stages of the game, we will ignore this for a moment and treat them as the parameters at this stage (indeed both $\alpha$ and $X$ are already given at this last stage of the game and so could be treated as the parameters). All possible market structures are depicted in Graph 1 together with the critical levels of $X$ as the function of $\alpha$ (that is, $X_{\alpha 1}, X_{\alpha 2}, X_{\alpha 1+}$ and $X_{\alpha 2+}$ ). We will focus here on the issue of eliminating the piracy by means of public IPR protection, acknowledging that it may not be always the optimal, social welfare maximizing strategy of the regulator. Thus, we stress at the outset that the analysis in this section is not normative but rather hypothetical with the aim of answering the following questions: i) how big should $X$ be (for the given $\alpha$ ) to just eliminate piracy ii) how big for the given $\alpha$ should $X$ be to completely eliminate the impact of piracy on pricing and market structure (that is, to achieve a pure, unconstrained duopoly) and, most importantly iii) what are the underlying mechanisms and tradeoffs involved in the issues described in i) and ii).

Answering these questions is not only interesting per se (for instance, the government might be bound to eliminate piracy by some international treaty), but it will, as we will see, also help us to better understand the regulator's choice of the optimal IPR protection.

Let us start with the easier case ii) of the complete elimination of the piracy 
captured by the function $X_{\alpha 2+}$ (see Graph 1) that is linear function, indicating that eliminating the pirated product becomes increasingly difficult as its quality increases. We refer to it as the "quality effect" of the pirated good. Putting it another way round, the lower the quality of the pirated good is vis-a-vis the original good $A$ that is copied, the easier it is to fully eliminate the effect of piracy on prices and market structure respectively.

The second effect (that we label "competition effect") is more subtle since the relevant levels of public protections needed to just eliminate piracy are captured by the non-monotonic functions $X_{\alpha 2}$ in $\alpha$ (see Graph 1). The reason is the nature of price competition where the distance between the qualities matter. To see that, let us start from the point where $X=0$ and $\alpha=\frac{q_{B}}{q_{A}}$ and describe the competitive forces around this point. For developer $B$ to be in the market it is necessary that he also introduces a bit of private protection (i.e., sets $\alpha$ at or slightly below $\alpha=\frac{q_{B}}{q_{A}}$ ) in order to capture some consumers with the valuation for product $B$ at the middle segment of the market. Note that for $\alpha$ slightly below $\frac{q_{B}}{q_{A}}$, the lower quality product $B$ competes with the illegal version of product $A$, which is a very close substitute to the legal version of product $B$ at this point, so the price competition is intense and therefore a rather small $X$, ("the price" of the illegal version) is enough to eliminate the pirated product from the market. As $\alpha$ decreases, the difference in quality between product $B$ and the illegal version of product $A$ becomes larger (favoring product $B$ ) so substitutability becomes poorer and, consequently, the competition softer and so a larger $X$ is needed to eliminate the piracy. This explains the falling part of $X_{\alpha 2}$ in Graph 1. To explain the increasing part of $X_{\alpha 2}$, note that beyond a certain point (that is left of the maximum of $X_{\alpha 2}$ ), the illegal version starts to become a closer substitute to the outside option as $\alpha$ goes towards 0 (or towards minimal possible value of $\alpha$ ) and so a lower $X$ is needed to eliminate the illegal version. Similar reasoning also applies to Case 1 and function $X_{\alpha 1}$ (see subsection 
6.4). Finally, note that when $X=0$ the ensuing market structure is a constrained monopoly by developer $A$ that we label as $m_{A}$.

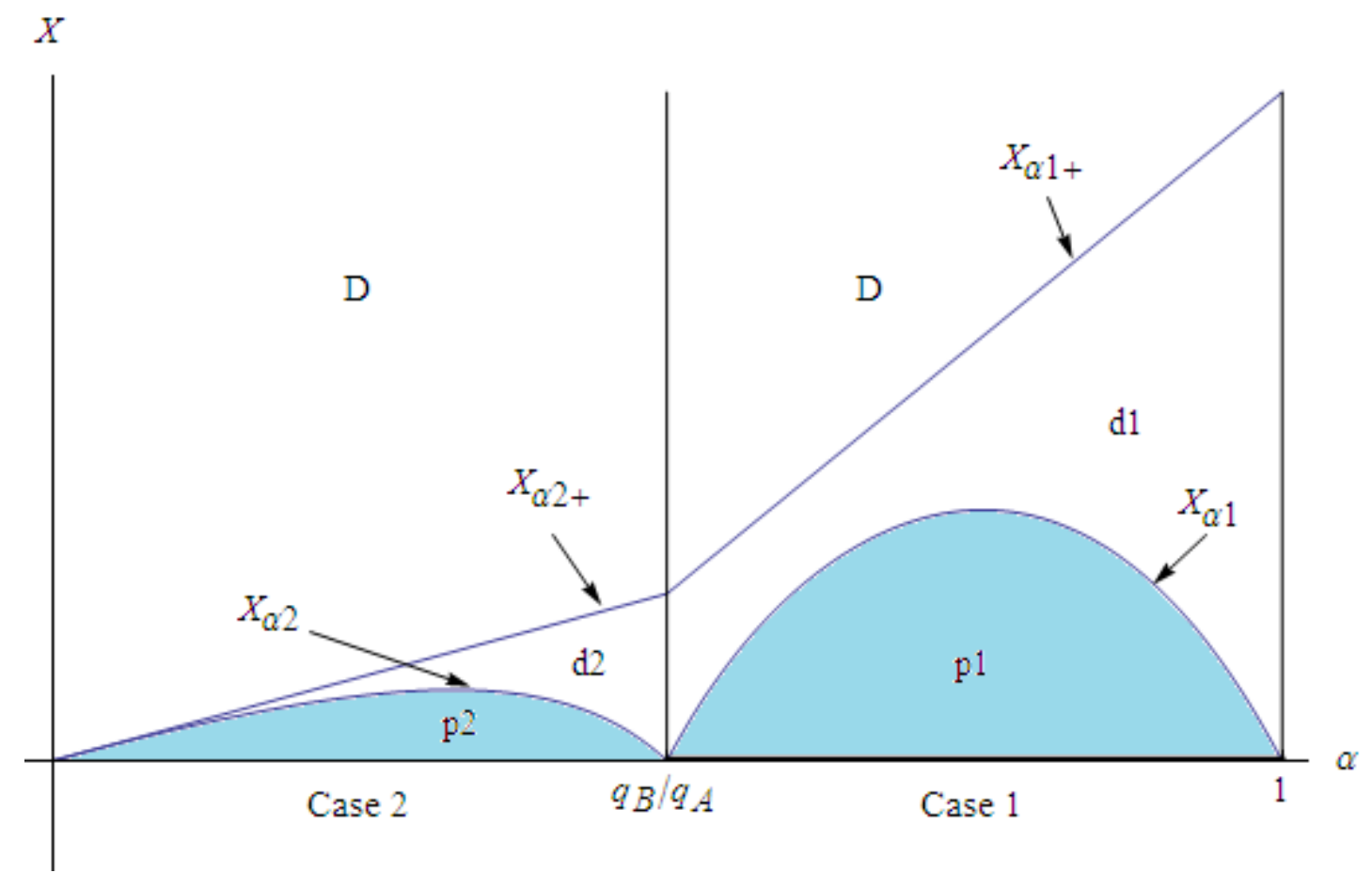

Graph 1

We summarize the above discussion in our first proposition:

\section{Proposition 1}

Private and public IPR protections are strategic substitutes if the regulator intends to fully eliminate piracy: decrease in private protection requires a proportional increase in public protection ("quality effect"). If, however, the purpose is to just eliminate piracy (while a potential threat of piracy still affects pricing and profits), then public and private IPR exhibit non-monotonic behavior being strategic complements for "lower" but strategic substitutes for "larger" levels of private protection ("competition effect"). 


\subsection{The second stage - the optimal firms' service restric- tions}

The optimal service restriction is rather simple in our set-up given the assumption of no costs for restraining services. Note that profit functions in both monopoly and duopoly decrease in $\alpha$. Thus, the maximal restriction of services to illegal users in a monopoly is optimal, that is $\alpha_{M}^{*}=\underline{\alpha}$. The same conclusion applies to the optimal service restriction in a duopoly, that is, $\alpha^{*}=\underline{\alpha}$ irrespective of the level of $X$ (provided that the size of $X$ is such that it requires the imposition of a service restriction by at least one developer, that is, $X<p_{A}$ ).

What is more interesting here is to see how $X$ and the optimal $\alpha$ affect the emerging market structure and market coverage in the second stage equilibrium. In the setup under consideration (Case 2), it would be optimal for both developers to introduce service restrictions such $\alpha_{A}^{*}=\alpha_{B}^{*}=\underline{\alpha}$. Let us assume now that the regulator sets an expected penalty that exceeds the critical value for Case 2 to occur, (that is, $X>X_{\alpha 2}$ ). In that case, $\frac{X}{\alpha q_{A}}>\frac{p_{B}}{q_{B}}\left(\right.$ or $\theta_{0 P}>\theta_{0 B}$ ) implying that no one would use an illegal version. Moreover, a pair of $\left(\underline{\alpha}, X_{\alpha 2+}\right)$ would restore a pure Bertrand competition. Note that $X_{\alpha 2+}$ is substantially lower than the expected penalty that would alone achieve complete elimination of illegal usage.

Note that developer $A$ may have an option in some situations to set a service restriction at, say, $\alpha_{1}>\underline{\alpha}$ such that $\alpha_{1} q_{A}>q_{B}\left(\right.$ while $\left.\underline{\alpha} q_{A}<q_{B}\right)$. Thus, the developer may opt to be in Case 1 and has to compare the profits from the two cases. It turns out, however, that for all feasible $\alpha$ and $X$, the relation between the optimal profits in the two cases is such that, $\pi_{A 2}^{*}(\underline{\alpha}) \geq \pi_{A 1}^{*}\left(\alpha_{1}\right)$ for all $\alpha \in[\underline{\alpha}, 1)$ and $X$ such that $X \leq X_{\alpha 1} \vee X \leq X_{\alpha 2}$ (where $\pi_{A i}^{*}$ stands for the profits in the two respected cases, $i=1,2)^{19}$.

\footnotetext{
${ }^{19}$ Namely, the equilibrium profit $\pi_{A}^{*}$ decreases in $\alpha$ for piracy equilibria in Case 1 , and for piracy and constrained non-piracy equilibria in Case 2. For the constrained non-piracy equilibria in Case
} 


\section{Optimal Public IPR Protection and Its Inter- action with Private IPR Protection}

\subsection{The first stage-optimal IPR protection}

Eliminating piracy might not necessarily be optimal from the social point of view. In this section we characterize socially optimal public IPR protection in general and tackle a different question: how the presence/absence of private IPR protection affects socially optimal IPR protection, $X^{*}$. Thus, we start with the issue of optimal IPR protection in the absence of private IPR protection. Note that it is optimal to completely give up public IPR protection when there is no private protection, that is, $X^{*}=0$ in this case. The reason is well known; there are zero marginal production costs for producing a unit of a (low or high) quality good. In addition, there are no restrictions on accompanying services and, consequently, no decrease in the perceived values of the product given the absence of private IPR protection.

The situation, however, changes dramatically, as we will see, when the developers introduce private protection. Thus, we first focus on solving the first stage of the game and on characterizing the optimal $X^{*}$ in the presence of private IPR protection.

We also continue to assume that private protection is not costly. So while private protection is endogenously chosen, it becomes de facto exogenous as the outcome of the developers' choice is $\alpha=\underline{\alpha}$ regardless of $X$.

The government's objective function is social welfare $W(X)$, which is comprised of the following components:

- Consumer surplus for each of the products potentially present in the market

1 , where there is equilibrium multiplicity, it can be shown that both maximum and minimum $\pi_{A}^{*}$ across the set of multiple equilibria at given $X$ decrease in $\alpha$. In addition, it is shown in Supplementary Material that the equilibrium in the model (viewed as a correspondence) is continuous in $X$ and $\alpha$, i.e., there is no discontinuity either between different equilibrium structures in Case 1 and Case 2 or between Case 1 and Case 2 at $\alpha=q_{B} / q_{A}$. This completes the proof that developer $A$ will always prefer $\alpha$ to be as low as possible. 
is given by $C S_{A}(X), C S_{B}(X)$ and $C S_{P}(X)$. Recall that if in equilibrium a product of quality $q$ is purchased by consumers with quality sensitivity $\theta \in$ $\left[\theta_{l}, \theta_{h}\right]$ at price $p$, then the consumer surplus generated by this product is given by

$$
C S=\int_{\theta_{l}}^{\theta_{h}}(\theta q-p) d \theta .
$$

It follows from the above that both legal products (or, under monopoly, the only legal product) are present in equilibrium, whereas the illegal product may or may not be present. Note that in the case of illegal product consumer surplus, $C S_{P}(X)$, is calculated by plugging $X$ instead of $p$ into the above formula.

- Expected penalty revenue $X \cdot D_{P}$, if the illegal product is present.

- Developers' profits, $\Pi_{A}(X)$ and (in the case of duopoly) $\Pi_{B}(X)$.

- Protection costs. In general, implementing the expected penalty level $X$ would cost $C(X)$. Recall that $C(0)=C^{\prime}(0)=0$ and $C^{\prime \prime} \geq 0$.

Thus for the general case that fits all other special cases, we have:

$$
\begin{aligned}
& W(X)=C S_{A}(X)+C S_{B}(X)+C S_{P}(X)+\Pi_{A}(X)+\Pi_{B}(X)+X \cdot D_{P}-C(X) \\
& \text { or } W(X)=G(X)-C(X)
\end{aligned}
$$

where $G(X)$ represents the gross social welfare, that is, $G(X)=C S_{A}(X)+$ $C S_{B}(X)+C S_{P}(X)+\Pi_{A}(X)+\Pi_{B}(X)+X \cdot D_{P}$.

In the first stage, the regulator chooses public protection in the form of the expected penalty level $X$ that maximizes the social welfare function, $W(X)$. The regulator faces the following short-run trade-off. On the one hand, lower values of $X$ (such that the outcome is not unconstrained monopoly or duopoly) increase market coverage and lower the social costs of IPR protection, so they have a positive 
impact on social welfare. On the other hand, low values of $X$ lead to higher shares of low-quality goods, which decreases consumer surplus and firms' profits and thus social welfare.

It can be shown that in all possible situations the social welfare function is continuous $^{20}$ in $X$, and, since the outcome for $X$ high enough, i.e, $X \geq X_{\alpha i+}$, is the classical Bertrand outcome (or the classical monopoly outcome), which does not depend on $X$, the welfare is bounded in $X$. Thus, social welfare attains a global maximum at $X=X^{*}$ such that $0 \leq X^{*} \leq X_{\alpha i+}$ for any cost function $C(\cdot)$ satisfying the restrictions above.

It is clear that the optimal $X$ when the public protection costs are $C(\cdot)>0$ cannot exceed the optimal $X$ when $C(X) \equiv 0$. For this reason, it seems insightful to characterize the optimal $X$ when there are no protection costs, that is, when $C(X) \equiv 0$. Note that this would define the upper bound of the optimal public protection. We then make an inference on what the optimal solution in the general case when $C(X)>0$ would be. Thus, before moving to the specific case of duopoly or monopoly, we first briefly discuss the general properties of optimal public IPR irrespective of the concrete market structure.

There are three situations to consider when $C(X) \equiv 0$ :

- $X^{*}=0$ If the optimal solution for $C(X) \equiv 0$ is $X^{*}=0$, it remains the same under non-zero public protection costs, that is for $C(X)>0$.

- $0<X^{*}<X_{\alpha i}$ (piracy equilibrium) If the optimal solution for $C(X) \equiv 0$ is interior in the area where the illegal product is present, it remains that way since in this case $\partial W / \partial X=\partial G / \partial X>0$ at $X=0$ while $C^{\prime}(0)=0$ (unless $W$ is maximized at $X=0)$.

- $X_{\alpha i} \leq X^{*} \leq X_{\alpha i+}$ (non-piracy equilibrium) If the optimal solution for $C(X) \equiv$

\footnotetext{
${ }^{20}$ As a correspondence, see Supplementary Material.
} 
0 is such that the illegal product is not present $\left(X^{*} \geq X_{\alpha i}\right)$, the equilibrium outcome may or may not change under non-zero protection costs. In particular, if the optimal solution for $C(X) \equiv 0$ is a constrained non-piracy equilibrium, then it may remain a constrained non-piracy equilibrium or switch to a piracy equilibrium, and if the outcome at $C(X) \equiv 0$ is an unconstrained non-piracy equilibrium, then it remains an unconstrained non-piracy equilibrium or switches to either a constrained non-piracy equilibrium or to a piracy equilibrium (however, the outcome cannot switch to zero public protection in either case since $\partial W / \partial X=\partial G / \partial X>0$ at $X=0)$.

Note that if $C(X) \equiv 0$ and welfare is maximized at $X=X_{\alpha i+}$, then any $X \geq$ $X_{\alpha i+}$ yields the same welfare value. However, $X>X_{\alpha i+}$ can never be optimal when $C(X)$ is non-zero. For this reason, we assume that if $C(X) \equiv 0$ and $X \geq X_{\alpha i+}$ is optimal, then $X=X_{\alpha i+}$ is chosen by the regulator.

The actual equilibrium outcome depends on the nature of the public protection costs, more specifically, on the steepness of the $C(X)$ function. For instance, if $C(X)$ increases very steeply in $X$ then the optimal $X$ may well be in the piracy range even though the optimal $X$ for for $C(X) \equiv 0$ would yield a non-piracy equilibrium.

\subsection{Monopoly}

We could envision the interaction between the regulator and the monopolist as a mixed Stackelberg duopoly in prices where the follower (a monopolist who maximizes profit) sets the price, $p_{M}$, after the leader (the regulator who maximizes social welfare) sets price $X$ (given that $\alpha=\underline{\alpha})^{21}$. It turns out that social welfare has an interior maximum, $X_{m}^{*}$, in the range of $X$ where the illegal product has a positive market share. So it is not optimal for the regulator to eliminate piracy because the

\footnotetext{
${ }^{21}$ See, for instance, Matsumura and Ogawa, 2014 on the issue of leadership in the context of a mixed duopoly (that is, the competition between a public and a private firm) in a sequential location model, and about the related literature on mixed duopoly.
} 
presence of the illegal version in the market dilutes monopoly power and enables consumers to choose between two varieties compared with the case with only one (more expensive) variety when piracy is eliminated. The social welfare increases in $\underline{\alpha}$ in all applicable cases: the better the "alternative" product, $\alpha q_{A}$, the higher the social welfare. Thus, the regulator would prefer no private (and consequently no public) protection, while the monopolist would prefer the strongest possible protection that fully eliminates the impact of piracy on the monopolist's profit. So there is a conflict of interest between the monopolist and the regulator.

More interestingly, public and private IPR protections act as strategic complements for weak private protection (that is, $\frac{d X_{m}^{*}}{d \underline{\alpha}}<0$ for $\underline{\alpha}>\alpha^{o}=2 / 3$ ), while for strong private protection the two protections are substitutes (that is $\frac{d X_{m}^{*}}{d \underline{\alpha}}>0$ for $\underline{\alpha}<\alpha^{o}$ ); see Graph 2 and Appendix III). Note that the optimal IPR protection is the implicit function of the optimal private IPR protection, that is, $X_{m}^{*}(\underline{\alpha})$.Thus, for $\underline{\alpha}$ close to unit, the legal version of software and its illegal copy are very close substitutes to each other, so the monopolist is forced to charge a very low price in order to be present in the market, and he earns only a slim profit due to the tough competition with the illegal version of the product. Given such intense competition, a very small increase in the price of the illegal product $X$ would be needed to eliminate piracy, yet it would be beneficial for consumers to have another variety to choose from. Therefore the regulator would optimally set $X$ below the level of public IPR protection, $X_{\alpha}$, that just eliminates piracy (see Graph 2). In other words, the gains in consumer surplus from not eliminating piracy dominate the losses in monopolist profit. If the monopolist could set somewhat stricter private protection, $\underline{\alpha}$, this would increase his profit and he would be rewarded with the larger $X_{m}^{*}$ (see Graph 2). This, in turn enables the monopolist to to further increase his profit and his prices. Thus, if optimal private IPR protection became stronger (that is, $\underline{\alpha}$ is falling towards $\underline{\alpha}^{o}$ ), both a monopolist's profit (which is also part of social welfare) 
and (in general) the consumer surplus of legal users would be further augmented via the greater optimal public IPR protection (see Graph 2). If, however, private IPR protection were strong enough that the actual $\underline{\alpha}$ lies below $\underline{\alpha}^{o}$, the competition between the legal and illegal product would be so weak that further softening of competition (via decrease in $\underline{\alpha}$ ), would squeeze the pirated goods market share too much. It would also increase monopolist market power too much compared to the social optimum. In this case, the optimal response would be to decrease public protection (that is, $\frac{d X_{m}^{*}}{d \underline{\alpha}}>0$ for $\underline{\alpha}<\underline{\alpha}^{o}$ ).

An alternative intuition relies on the competition effect (already described in subsection 5.4.). Note that if $\underline{\alpha}$ could be stretched all the way towards zero, then what matters is not the (very weak) competition of the pirated version with its legal version, but the fact that it might be better for a consumer not to buy anything rather than to acquire a very poor copy of the original version. This becomes more so the closer $\underline{\alpha}$ is to 0 . One can also think that there is an outside option available to consumers with a price of zero and that now competes with the illegal version. This outside option becomes more attractive for consumers as $\underline{\alpha}$ would be closer to zero. In such a situation, the $X_{\alpha}$ needed to eliminate piracy becomes smaller as $\underline{\alpha}$ approaches zero. Consequently, $X_{m}^{*}(\underline{\alpha})<X_{\alpha}$ in order to preserve a share of the illegal users in the market, but also $X_{m}^{*}(\underline{\alpha})>0$ to enable the monopolist to be active in the market and to earn positive profit. This explains the increasing part of $X_{m}^{*}(\underline{\alpha})$ in the interval $0<\underline{\alpha}<\underline{\alpha}^{o}$ (see Graph 2). 


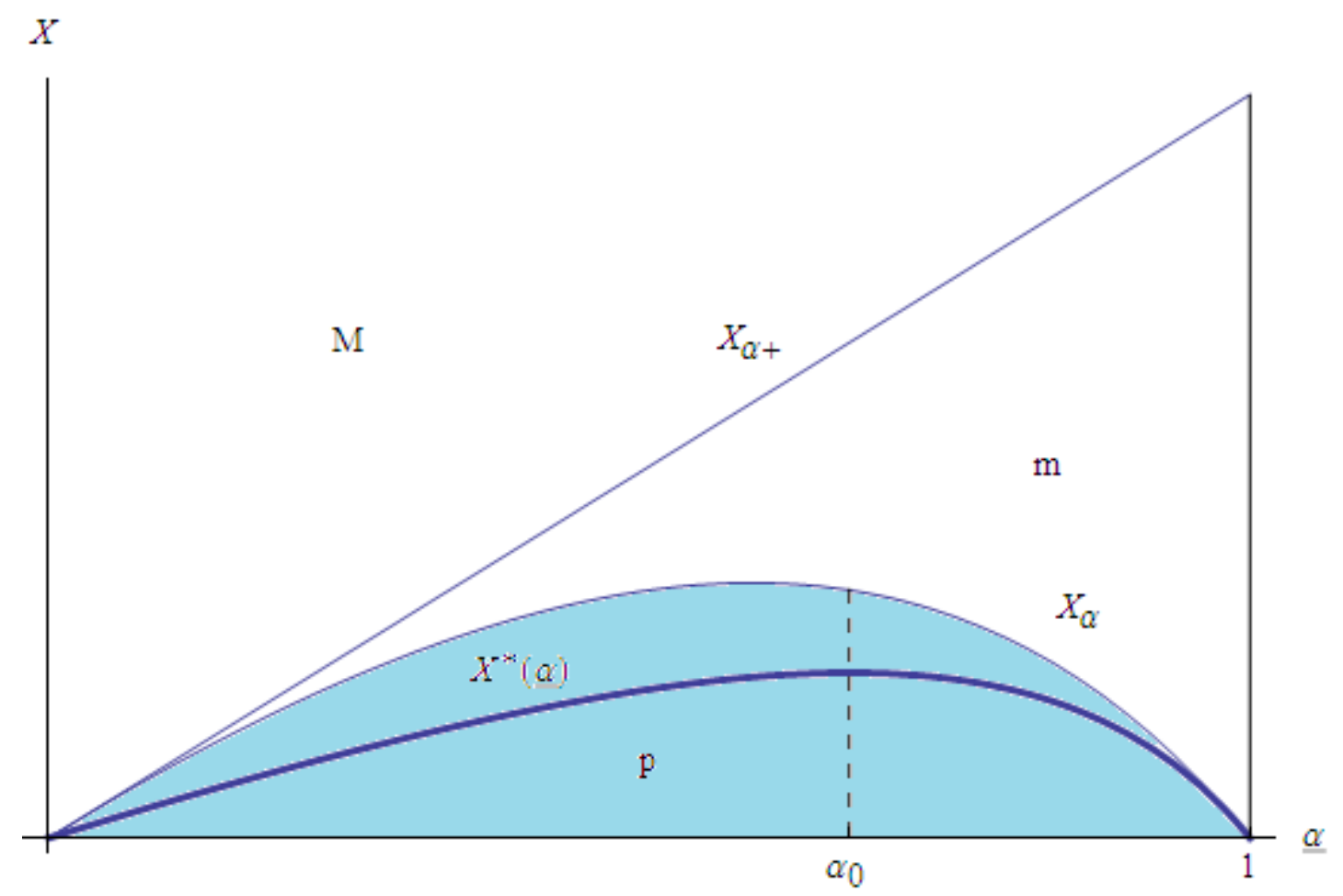

Graph 2

\section{Proposition 2}

There is conflict of interest between the monopolist and the regulator. The regulator prefers no private (and, consequently) no public protection while the monopolist prefers the strictest private IPR protection and would like the regulator to set the highest possible public protection. For low private protection $\left(\underline{\alpha}>\underline{\alpha}^{o}\right)$, the private and public IPR protections act as strategic complements implying that stronger private protection would be associated with stronger public protection. For $\alpha<\underline{\alpha}^{o}$ there is strategic substitutability between the two forms of protections.

\subsection{Duopoly}

We next focus on social welfare considerations in a duopoly. It turns out that social welfare is maximized at $X=X_{\alpha 2+}$ when $C(X) \equiv 0$, (see Appendix III) or when $C(X)>0$ but the protection costs are not "very sensitive" to increase in 
$X$. The socially optimal outcome is then a classical Bertrand duopoly $(D)$ - see Graph 3. The reason is that the illegal product is the worst one, and a possible gain in market coverage due to its presence cannot offset the welfare lost due to other consumers switching to lower qualities and loss in profits. Thus, unlike in a monopoly, there is no trade off between the overall product quality in the market and firms' profits, so the regulator chooses the boundary solution resulting in an unconstrained duopoly. Of course, if increase in $X$ causes protection costs to rise rather steeply, then $X_{\alpha 2} \leq X^{*}<X_{\alpha 2+}$ or there is an interior (piracy) optimum $X^{*}$ such that $0<X^{*}<X_{\alpha 2}$.

Note that these results are in sharp contrast to the analogous result in monopoly. There is no conflict of interest between the regulator and the developers since social welfare decreases in $\alpha$ for $X<X_{\alpha 2+}$. The lower $\alpha$, the easier it is for the legal products to compete with the inferior illegal product; in other words, the higher $\alpha$, the more difficult it is to drive the illegal product out of the market and, since this is the product of the lowest quality, its presence is harmful to social welfare.

We summarize the above findings in our third proposition:

\section{Proposition 3}

The interests of the developers and the regulator are aligned because all of the actors' payoffs increase with stricter private protection and with shrinking or eliminating the lowest quality piracy product. The private and public IPR protections act as strategic substitutes implying that stronger private protection would be associated with lower public protection.

Finally, our analysis yields the testable hypothesis that the regulator would be less willing to tolerate piracy if there is a duopoly as opposed to a monopoly since now the illegal product is of the lowest quality, and would completely eliminate piracy (and its influence on prices and profits) if the costs of elimination are not 
"too large".

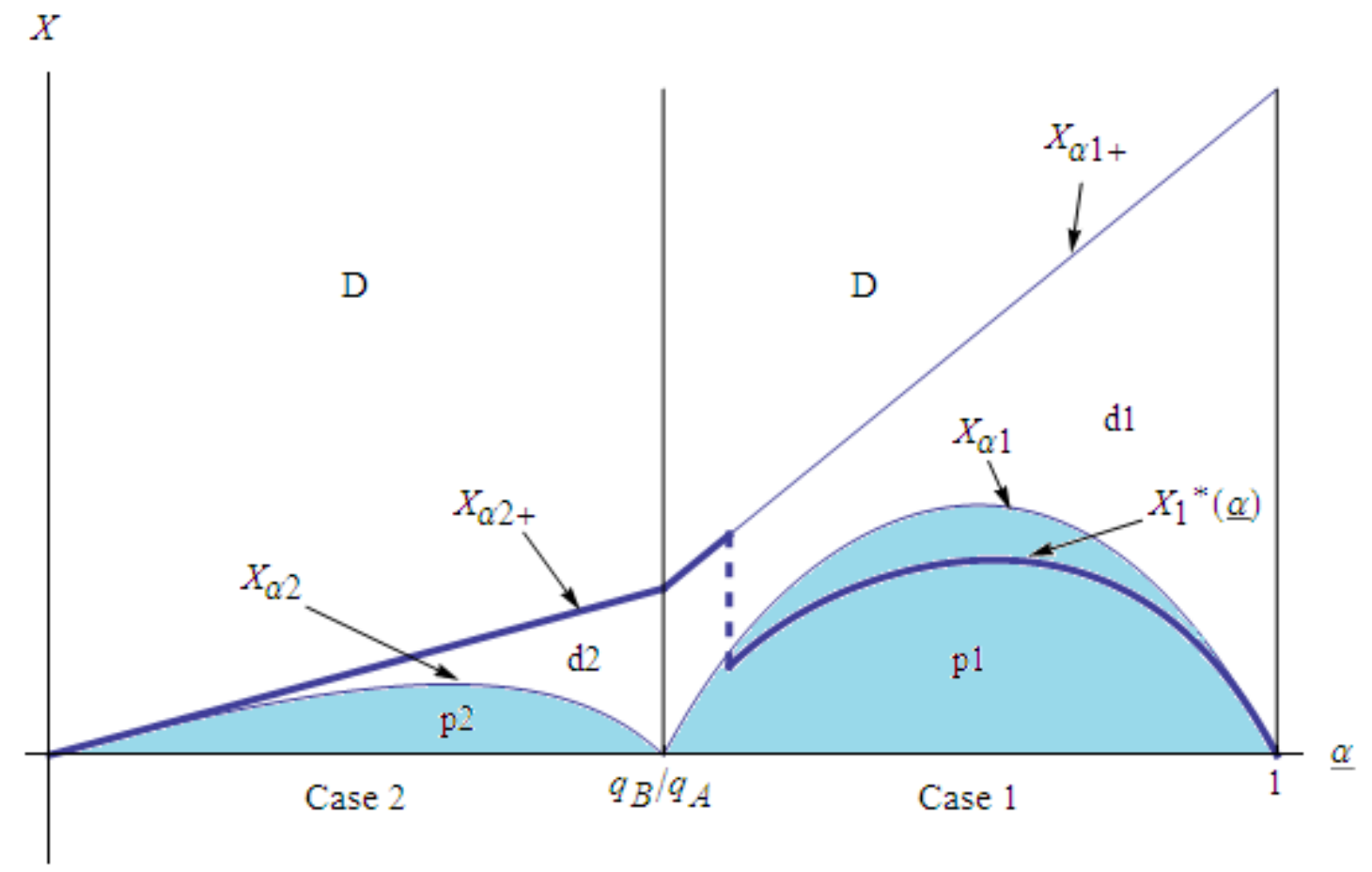

Graph 3

\subsection{The interaction between the optimal private and public IPR protections}

After having characterized the optimal public IPR protections in both monopoly and duopoly, we are ready to summarize our key insights regarding the interaction between private and public IPR at the social optimum. Now we can ask what would happen with the optimal public IPR protection if we allow for private IPR protection at the margin. Technically, this would mean that $\underline{\alpha}$ drops beneath unit by some infinitesimal amount. It turns out the very appearance of small optimal private protection induces positive public protection. We have noted this fact in our last proposition: 


\section{Proposition 4}

The very appearance of private IPR protection (that is, $\underline{\alpha}$ close to 1 ) leads (at the margin) to positive public IPR protection indicating that public and private IPR protections are complements at that point. For larger private IPR protection (low $\underline{\alpha}$ ) the two forms of IPR protection become substitutes. Thus, there is a non-monotonic relation between public and private IPR protection.

Proof. Given $W(X)=G(X)-C(X)$ and $\frac{\partial W}{\partial X}=0$, by the implicit function theorem $\frac{d X^{*}}{d \underline{\alpha}}=-\frac{\frac{\partial G^{2}\left(X^{*}\right)}{\partial X \partial \alpha}}{G^{\prime \prime}\left(X^{*}\right)-C^{\prime \prime}\left(X^{*}\right)}$ as $C(X)$ does not depend on $\alpha$. By the second-order condition, $G^{\prime \prime}\left(X^{*}\right)-C^{\prime \prime}\left(X^{*}\right)<0$, and it can be easily shown that $\partial G^{\prime}\left(X^{*}\right) / \partial \underline{\alpha}<0$ at $\underline{\alpha}=1$. Thus, $\frac{d X^{*}}{d \underline{\alpha}}(\underline{\alpha}=1)<0$.

In particular, it is optimal to have no public protection when the pirated product is as good as the highest-quality legal product in the market $(\underline{\alpha}=1)$, but it becomes optimal to introduce positive public protection as soon as $\underline{\alpha}<1$, because the pirated product becomes, if slightly, inferior to the legal product $A$. It is important to observe that this result is more general than it appears since it is not only confined to a monopoly but also to the situation of a duopoly at which the pirated version of the high quality good has higher perceived quality than the low quality good, $B$ (that is $q_{B}<\alpha q_{A}$; recall the Case 1 ). Thus, raising public protection from zero to some positive number not only allows monopolist $A$ to be active in the market, but in the case of duopoly, it also enables firm $B$ to serve the lowest tail of the market (in addition, it brings some revenue to the government). With the public protection moving from zero to some "small" positive level of $X$ there is an increase in the number of variates in the market because some low-end consumers switch from the pirated good $A$ to the legal good $B$. So there are now three goods available to consumers: good $A$, the pirated version of good $A$, and good $B$ (compared with only two goods before when only private protection was in place- software $A$ and 
its pirated version). Thus welfare improvement stems from the increase in profit of both firms and an increase in consumers' surplus of the legal users.

Much like in the case of a monopoly (see subsection 6.2), the intuition of such a non-monotonic response could be associated with the competition effect. The higher the private IPR protection (the lower $\underline{\alpha}$ ), the poorer a substitute the legal version of software is with its illegal copy, and, as we already know, the softer is the competition and a larger $X$ is needed to eliminate piracy (see subsection 6.2). It is, however, not optimal for the regulator to eliminate the pirated version since it is still of a higher quality than the software $B$, nor it is optimal to put $X$ at zero since this prevents firm $B$ from operation and hampers the profits of firm $A$. Thus the regulator picks a value of $X$ that is positive but lower than $X_{\alpha 1}$ and this optimal value of public protection increases in $\underline{\alpha}$ as competition between good $A$ and its pirated version becomes softer. This consequently enables the regulator to boost the profits of the two developers (and typically also the consumer surplus of legal users) with stronger public protection without fully eliminating the mid-quality pirated product. This mechanism, however, does not work beyond the value $\underline{\alpha}^{m}$ of the private protection. While it is true that competition between good $A$ and its pirated version becomes very soft for a low $\underline{\alpha}$, what matters most in this situation (when $\underline{\alpha}<\underline{\alpha}^{m}$ ) is the competition between the pirated version of product $A$ and the legal version of product $B$, as now these two products become closer substitutes with $\underline{\alpha}$ moving towards $q_{B} / q_{A}$ (at $\underline{\alpha}=q_{B} / q_{A}$ both products are perfect substitutessee Graph 3). As this competition becomes tougher, the level of $X$ needed to just eliminate piracy becomes lower and consequently the optimal IPR response to it, $X_{1}^{*}(\underline{\alpha})$, falls as well in $\underline{\alpha}$, thus explaining the substitutability between the two forms of protection that occurs in the range $\underline{\alpha} \in\left(q_{B} / q_{A}, \underline{\alpha}^{m}\right)^{22}$.

\footnotetext{
${ }^{22}$ When the qualities of the pirated version of good $A$ and the legal version of good $B$ are "very close", it pays off for the regulator to adopt a more aggressive approach and completely eliminate piracy so that the optimal public IPR protection jumps to $X_{\alpha 1+}$ (dotted line in Graph 3$)$. The
} 
In the standard duopoly that we focus on in this paper (Case 2), the mechanism at work is a much simpler quality effect. Private and public IPR protection are always strategic substitutes (as is evident in Graph 3) and the optimal market structure is a pure duopoly. Thus the larger the quality of the pirated good, the greater the public IPR protection must be, to result in the socially optimal full elimination of piracy (and unconstrained duopoly). Note that this effect does not appear in the welfare considerations under monopoly. Finally, the corollary of Proposition 4 is that it would be socially optimal to give up public protection in the absence of private IPR protection (that is, $X^{*}=0$ for $\underline{\alpha}=1$ ) or alternatively, the zero public IPR protection ceases to be optimal when there is private IPR protection.

\section{The Long-Run Aspect and the Optimal Public IPR}

We now briefly comment on the choice of qualities in our setups: monopoly and duopoly. In order to account for the firms' long-run decisions, it would be necessary to add an interim stage in our previously considered setup. The key issue here is what would be appropriate sequencing of moves, that is, at which stage the choice of qualities has to be placed, in this four-stage game now. One can, for instance, argue that the government should be able to commit to a level of public IPR protection before the developers set their qualities. This would imply that the choice of qualities would occur only after the regulator sets the optimal $X$. The problem with this approach, however, is that it might be difficult to commit to a particular level of expected penalty given its stochastic nature (even though there is

pirated version of $A$ and the legal version of product $B$ are almost perfect substitutes then, so the loss in the consumer surplus and in the expected revenue is relatively small compared to the gain in the developers' profits due to the absence of piracy (see Žigić, et al, 2013 for more on this case). 
definitely a general government commitment to fight software piracy and to protect IPR through say, copyright). This suggests that an alternative approach focusing on the non-committed regulator deserves close scrutiny. Thus, the developer(s) set(s) quality anticipating (or better to say, inducing) the expected penalty that the regulator will set ex post after it observes the chosen quality. Indeed this setup could be seen as the natural extension of the three-stage game that we analyzed. While this approach is more realistic, we, on the other hand, cannot make a direct comparison with the short-run level of the optimal public IPR protection derived in the previous section.

We therefore stick to the assumption that a regulator can commit to a level of IPR (like in Bae and Choi, 2006) and start with a monopoly setup. We show that in the short-run equilibrium the regulator does affect monopoly pricing and profits (see the subsection 6.2). More specifically, it is socially optimal to set an $X$ that is not large in order to avoid fully eradicating piracy since it restrains monopoly pricing. From the long-run perspective, however, the presence of piracy generates disincentives to enhance the quality level but such an increase in quality would be socially optimal and it was not taken into account in our short-run optimization. Thus, it is clear that the socially optimal level of the public IPR would be higher when the regulator takes into account the disincentivizing effect of piracy on the choice of quality (see Bae and Choi, 2006). Incorporating the quality choice would also require adding the costs of achieving a particular quality level, $C(q)$ such that $C \prime(q)>0$ and $C \prime \prime(q)>0$. For instance, we could postulate that $C(q)=\frac{a q_{i}^{2}}{2}$ in our setup and it would be easily seen that, much like in Bae and Choi, 2006, the public optimal long-run, IPR protection, $X^{* *}>X^{*}$ in case of monopoly. Moreover, in this specific setup the size of $X^{* *}$ would require full piracy elimination.

Note that the above conclusion does not extend to the considered case of a duopoly. The reason is that the short-run optimal level of IPR in duopoly is al- 
ready so high (for zero or slowly increasing monitoring costs) that it induces the unconstrained duopoly setup for the short-run social welfare (it increases in $X$ until an unconstrained duopoly is reached). It can be shown that under very general conditions this holds in the long run as well. Thus, unlike in the case of monopoly, there is no disincentivizing effect of piracy and, so there is no difference between the short and the long run level of the optimal public IPR protection.

\section{Conclusion}

We study the modeling of software piracy and their economic implications in two different market structures under considerations: a monopoly and a duopoly setup. We argue that in some software markets direct competition between the developers might be empirically relevant so the duopoly competition might be more realistic and thus a more relevant market structure to consider. In the context of the above mentioned market structures, we focus on economic interaction between two instances of IPR protections and their positive and normative implications. The first instance is associated with the level of public protection that comes in the form of an expected penalty for violating IPR. The second instance represents private IPR protection at the level of the developer in the form of restricting additional consumer services for illegal users. This discourages illegal usage and makes it less attractive. Thus, we examine the market equilibria with the above form of IPR protections and their social welfare implications.

As for the normative analysis, we focus on the welfare maximizing choice of public IPR protection and its economic impacts in the setup where product qualities are given (short-run aspect!). We show that the absence of public IPR protection ceases to be optimal (from the social point of view) when private IPR protection is present. Moreover, the appearance of private IPR protection at the margin leads 
to positive public IPR protection in equilibrium indicating that public and private IPR protections are complements at that point. For private IPR protection at a rather high level, however, public and private IPR protections may act again as substitutes. More generally, we identify two distinct effects that are beneath these interactions: i) quality and ii) competition effects and, depending on the parameter setup, one or another of these effects governs the optimal choice of public IPR. While the competition effect appears in the case of social welfare maximization in a monopoly, the quality effect appears only in duopoly welfare considerations and is thus a distinctive feature of this setup.

The optimal value of the expected penalty is in general positive and depending on the case under consideration and properties of protection costs, may or may not be associated with the presence of illegal goods in the market. Finally, we show that the primary role of public IPR protection in our set-up is to ensure the presence of a larger share of legal products in the market compared with the situation of no IPR protection, thus boosting the developers' profits and the consumer surplus of legal users, at the expense of the consumers surplus of illegal users. In other words, the function of IPR protection in the short run is not to restore incentives to invest in $R \& D$ and enhance the quality of the product but i) to increase the presence of higher quality products in market equilibrium and ii) to boost the profits of the firms. So the duty of the regulator is to manage potential trade off between these two effects in order to maximize social welfare.

It should, in principle, be possible to extend our normative analysis to the longrun issue of quality choice. It turns out that the optimal short-run public protection in monopoly is insufficient in the long-run since it allows for piracy and thus does not take into account the disincentive to invest in better quality. This, however, is not the case in a duopoly where the optimal short-run IPR protection implies unconstrained duopoly (given zero or slow increasing monitoring cost) and so it 
does not adversely affect the incentive to invest in R\&D and better quality.

The equilibrium market structure is always an unconstrained duopoly (under zero or slowly increasing IPR costs in $X$ ) even though a constrained non-piracy duopoly or even a piracy duopoly could appear due to a fast increase of public IPR costs in $X$.

As for the potential conflict of interests among the stakeholders, the interests of the developers and the regulator are aligned in the duopoly under consideration, because all of the actors' objective functions increase with stricter private protection and with the shrinkage or elimination of the lowest quality pirated product. In a monopoly, however, the interests are opposite: the regulator prefers no private protection and would like to tolerate piracy (recall that zero private protection would be optimally matched with zero public protection) while the monopolist would like the regulator to set public protection as high as possible.

Finally, one of the possible modifications and robust checks of our model would be to analyze the interaction between public and private IPR protection when the latter comes in the form of physical protection. This form (although a bit controversial) is still used to protect software by preventing illegal users from having any value of a pirated good (this would be equivalent to setting $\alpha$ to zero in our set-up) but, on the other hand, there is no perfect IPR protection, so a certain fraction of skilled users would be always able to circumvent such a protection. Thus the issue at stake now would be how public protection affects costly private physical protection and what would the social welfare implications of this be. 


\section{APPENDICES}

\section{Appendix I}

\subsection{General notes}

Most of the calculations in this paper were performed using Mathematica and other similar software. The Mathematica file is available upon request.

In almost all model situations here, profit functions are concave (quadratic, or, in singular cases, linear) in the respective choice variables, so that an interior solution is always a (local) maximum. Thus, second-order conditions always hold so they are omitted everywhere below.

\subsection{Indifferent users}

As usual, the notation $\theta_{Y Z}$, where $Y$ and $Z$ can be one of $\{0, A, B, I\}$ implies that the users with $\theta<\theta_{Y Z}$ strictly prefer $Y$ to $Z$, and the users with $\theta>\theta_{Y Z}$ strictly prefer $Z$ to $Y$. Throughout this appendix, "product $P$ " refers to the illegal version of product $A$.

As in the basic model, for thresholds not involving the illegal version of product $A$,

$$
\theta_{0 A}=\frac{p_{A}}{q_{A}}, \theta_{0 B}=\frac{p_{B}}{q_{B}}, \theta_{B A}=\frac{p_{A}-p_{B}}{q_{A}-q_{B}}
$$

For thresholds involving product $P$ but not involving product $B$,

$$
\theta_{0 P}=\frac{X}{\alpha q_{A}}, \theta_{P A}=\frac{p_{A}-X}{q_{A}-\alpha q_{A}}
$$

As for the threshold between $B$ and $P$, two cases have to be distinguished. First, the quality reduction to illegal users can be relatively low so that $P$ is still better than 
$B$, i.e., $q_{B}<\alpha q_{A}$. Second, the quality reduction to illegal users can be relatively high so that illegal $A$ becomes worse than $B$, i.e., $q_{B}>\alpha q_{A}$. (If $q_{B}=\alpha q_{A}$, then it is impossible that both $B$ and $P$ are in the market, and we concentrate on the cases where all three products are present.) In the first case, users with sensitivity below the threshold use $B$ whereas those above use $P$, so we use notation $\theta_{B P}$. In the second case, the situation is the opposite so we use notation $\theta_{P B}$. These are equal to

$$
\theta_{B P}=\frac{X-p_{B}}{\alpha q_{A}-q_{B}}, \theta_{P B}=\frac{p_{B}-X}{q_{B}-\alpha q_{A}}
$$

(Mathematically, these two are identical.)

\subsection{Monopoly}

The relevant thresholds are $\theta_{0 A}, \theta_{0 P}$, and $\theta_{P A}$. Two cases are possible. First, if $p_{A} \leq \frac{X}{\alpha}$, then $\theta_{P A} \leq \theta_{0 A} \leq \theta_{0 P}$ (equality holds everywhere or nowhere) so that $P$ is out of the market and users buy either $A$ or nothing. Second, if $p_{A}>\frac{X}{\alpha}$, then $\theta_{P A}>\theta_{0 A}>\theta_{0 P}$ so that both $P$ and $A$ are in the market as in Figure 1.

The monopolist's profit can be shown to be unimodal, and three outcomes can be distinguished.

First, if $X \geq \frac{1}{2} \bar{\theta} \alpha q_{A}$, then the unconstrained monopoly price is such that the illegal product is ousted, so that

$$
p_{A}^{*}=\frac{\bar{\theta} q_{A}}{2}, \pi_{A}^{*}=\frac{\bar{\theta}^{2} q_{A}}{4} .
$$

Second, if $X$ is in the piracy range, that is, $X<\bar{\theta} \alpha q_{A} \frac{(1-\alpha)}{2-\alpha}$, then both $A$ and $P$ are present so that

$$
p_{A}^{*}=\frac{X+\bar{\theta} q_{A}(1-\alpha)}{2}, \pi_{A}^{*}=\frac{1}{4} \frac{\left(X+q_{A} \bar{\theta}(1-\alpha)\right)^{2}}{q_{A}(1-\alpha)} .
$$


Third, if $X$ is in the constrained monopoly range, that is, $\bar{\theta} \alpha q_{A} \frac{(1-\alpha)}{2-\alpha} \leq X<$ $\frac{1}{2} \bar{\theta} \alpha q_{A}$, then while the monopolist has to lower the price due to the possibility of illegal use, this illegal use is still eliminated at the optimum, namely

$$
p_{A}^{*}=\frac{X}{\alpha}, \pi_{A}^{*}=\frac{X}{\alpha}\left(\bar{\theta}-\frac{X}{\alpha q_{A}}\right)
$$

\subsection{Bertrand competition}

See Supplementary Material for a complete mathematical treatment. The outcomes for all sub-cases except for the constrained non-piracy outcome in Case 1 can be found in the main text. As for the remaining sub-case, it is shown in Supplementary Material that in case 1 , if $X_{\alpha 1}<X<X_{\alpha 1+}$ then a pair of prices $\left(p_{A}, p_{B}\right)$ is a constrained non-piracy equilibrium if and only if $\theta_{B P}=\theta_{P A}$ and $p_{A-}(X) \leq p_{A} \leq$ $p_{A+}(X)$, where the boundaries $p_{A-}(X)$ and $p_{A+}(X)$ are determined in the following way.

$p_{A-}(X)=\left\{\begin{array}{ll}p_{A L}, & X_{\alpha 1}<X \leq X_{\alpha 1 L}, \\ p_{A l}, & X_{\alpha 1 L}<X<X_{\alpha 1+},\end{array} \quad, \quad p_{A+}(X)= \begin{cases}p_{A h}, & X_{\alpha 1}<X \leq X_{\alpha 1 H} \\ p_{A H}, & X_{\alpha 1 H}<X<X_{\alpha 1+}\end{cases}\right.$

where the symbols used are

$$
\begin{gathered}
p_{A L}=\frac{X+\bar{\theta}\left(q_{A}-\alpha q_{A}\right)}{2}, p_{A l}=2 X \frac{q_{A}-q_{B}}{2 \alpha q_{A}-q_{B}-\alpha q_{B}}, \\
p_{A h}=X \frac{2 \alpha q_{A}-q_{B}-\alpha q_{B}}{2 \alpha\left(\alpha q_{A}-q_{B}\right)}, p_{A H}=\frac{\left(X+\bar{\theta}\left(q_{A}-\alpha q_{A}\right)\right)\left(q_{A}-q_{B}\right)}{2 q_{A}-q_{B}-\alpha q_{A}}, \\
X_{\alpha 1 L}=\bar{\theta} q_{A} \frac{(1-\alpha)\left(2 \alpha q_{A}-q_{B}-\alpha q_{B}\right)}{(4-2 \alpha) q_{A}-(3-\alpha) q_{B}}, \\
X_{\alpha 1 H}=\bar{\theta} q_{A} \frac{2 \alpha\left(q_{A}-q_{B}\right)\left(\alpha q_{A}-q_{B}\right)}{4 \alpha q_{A}^{2}-(2+3 \alpha) q_{A} q_{B}+q_{B}^{2}} .
\end{gathered}
$$




\section{Appendix II: Costly Private Protection}

When it is costly for developers to undertake private protections, then two basic situations arise: first, if the costs do not increase "too fast" with the degree of private protection, then there will again be a corner solution, $\alpha^{*}=\underline{\alpha}$, discussed in the main text. Second, if this is not the case, then it would be reasonable to argue that the private IPR cost function, $C(\alpha)$ is convex enough to generate an interior maximum. So we postulate that $C^{\prime}(\alpha)<0$ (recall that the costs increase as $\alpha$ falls) and that $C^{\prime \prime}(\alpha)>0$. Finally, the optimal $\alpha$ can be again in the range of $[\underline{\alpha}, 1)$ or, alternatively (but less realistically) anywhere in the interval $(0,1)$.

We now write the net profit function of developer $A$ as a function of $\alpha$ in both cases $i=1,2$ as $\Pi_{A i}^{N}(\alpha)=\Pi_{A i}^{*}-C(\alpha)$ where the second-order condition $\frac{\partial^{2}}{\partial \alpha^{2}} \Pi_{A i}^{N}(\alpha)<0$ holds because of the assumption that $C(\alpha)$ is "convex enough" .

Differentiating the first-order condition $\frac{d \Pi_{A i}^{N}(\alpha[X], X)}{d \alpha} \equiv 0$ with respect to $X$ and solving for $\frac{d \alpha^{*}}{d X}$ we obtain that $\frac{d \alpha^{*}}{d X}=-\frac{\frac{\partial^{2}}{\partial \alpha \partial X} \Pi_{A i}^{N}(\alpha)}{\frac{\partial^{2}}{\partial \alpha^{2}} \Pi_{A i}^{N}(\alpha)}=\operatorname{sign}\left[\frac{\partial^{2}}{\partial \alpha \partial X} \Pi_{A i}^{N}(\alpha)\right]$.

It is straightforward to show that $\frac{\partial^{2}}{\partial \alpha \partial X} \Pi_{A i}^{N}(\alpha)>0$. For, instance, in the Case 1 where the only the developer $A$ undertakes protection,

$$
\frac{\partial^{2}}{\partial \alpha \partial X} \Pi_{A 1}^{N}(\alpha)=\frac{X}{2 q_{A}(1-\alpha)^{2}}>0 .
$$

For the Case 2, the expression is a little bit more complicated where we write the cross-partial derivative of the producer's $A$ profit as the product of two expressions: $\frac{\partial^{2}}{\partial \alpha \partial X} \Pi_{A 2}^{N}(\alpha)=\frac{4 q_{A}\left(q_{A}-q_{B}\right)}{\left(q_{A}(3 \alpha-4)+q_{B}\right)^{3}} \times\left(-3 X-\bar{\theta}\left(q_{B}+q_{A}(2-3 \alpha)\right)\right.$. Note that both expressions are negative given the Case 2 requirement that $q_{B}>\alpha q_{A}$, yielding $\frac{\partial^{2}}{\partial \alpha \partial X} \Pi_{A 2}^{N}(\alpha)>$ 0. Using similar approach also yields $\frac{\partial^{2}}{\partial \alpha \partial X} \Pi_{B 2}^{N}(\alpha)>0$.

Thus, the private and public IPR are substitutes even if private IPR protection is obtained as an interior maximum. The only difference compared with the situation of non-costly private IPR protection is that now the marginal change in $X$ affects the optimal private IPR protection. That is, an increase in public IPR protection 
requires the softening (larger $\alpha^{*}$ ) of the optimal private IPR protection.

\section{Appendix III: Optimal Public Protection}

\section{$3.1 \quad$ Monopoly}

In the piracy range of monopoly, (that is, $\left.X<\bar{\theta} \alpha q_{A} \frac{(1-\alpha)}{2-\alpha}\right)$, the marginal social welfare is given as:

$$
\frac{\partial W}{\partial X}=\frac{1}{4}\left(\bar{\theta}-X\left(\frac{4-3 \alpha}{\alpha(1-\alpha) q_{A}}\right)\right)
$$

Note that $\partial W / \partial X>0$ at $X=0$, while $\partial W / \partial X<0$ at $X=\bar{\theta} \alpha q_{A} \frac{(1-\alpha)}{2-\alpha}$. In addition, social welfare strictly decreases in $X$ in the constrained monopoly range, $\bar{\theta} \alpha q_{A} \frac{(1-\alpha)}{2-\alpha}<X<\frac{1}{2} \bar{\theta} \alpha q_{A}$, and is constant in $X$ in the unconstrained monopoly range $X \geq \frac{1}{2} \bar{\theta} \alpha q_{A}$. Thus, if only one developer is present in the market, then the socially optimal level of public protection is always (except for $\alpha=0$ and $\alpha=1$ ) reached inside the piracy range, $X<\bar{\theta} \alpha q_{A} \frac{(1-\alpha)}{2-\alpha}$,so the socially optimal level of $X$ is always positive (even if $C(\cdot)>0$ given that $C^{\prime}(0)=0$ ). Thus, $X^{*}=\frac{\bar{\theta} q_{A}(1-\alpha) \alpha}{4-3 \alpha}$. Finally, note that $X^{*}=0$ at $\alpha=0$ and $\alpha=1$, and $X^{*}(\alpha)$ increases in $\alpha$ for $\alpha<2 / 3$, and decreases in $\alpha$ for $\alpha>2 / 3$.

\section{$3.2 \quad$ Case 2}

In the piracy range of case $2, \partial W / \partial X=\left(\Omega_{X} X+\Omega_{0}\right) / \Omega_{D}$, where

$$
\begin{aligned}
& \Omega_{X}=q_{A}^{3} \alpha(12-11 \alpha)-q_{A}^{2} q_{B}\left(16-11 \alpha+2 \alpha^{2}\right)+q_{A} q_{B}^{2}(8-5 \alpha)-q_{B}^{3} \\
& \Omega_{0}=4 \alpha(1-\alpha) q_{A}^{2}\left(q_{A}-q_{B}\right)\left(q_{B}-\alpha q_{A}\right) \bar{\theta} \\
& \Omega_{D}=\alpha q_{A}\left(q_{B}-\alpha q_{A}\right)\left(q_{A}(4-3 \alpha)-q_{B}\right)^{2}
\end{aligned}
$$


This is clearly positive at $X=0$, linear in $X$, and can be shown to be positive at $X=X_{\alpha 2}$. Thus, welfare increases in $X$ in the piracy range of case 2 .

In the constrained non-piracy range of case 2 ,

$$
\frac{\partial W}{\partial X}=\frac{q_{B}\left(\alpha q_{A}\left(q_{A}-q_{B}\right) \bar{\theta}-X\left(4 q_{A}-3 q_{B}\right)\right)}{4 \alpha^{2} q_{A}^{2}\left(q_{A}-q_{B}\right)} .
$$

This is linear and decreasing in $X$, and can be shown to be positive at $X=X_{\alpha 2+}$. Thus, welfare increases in $X$ in the constrained non-piracy range of case 2 , which completes the proof that if $C(\cdot) \equiv 0$ in case 2 , then welfare is maximized at $X=$ $X_{\alpha 2+}$. 


\section{References}

Ahn, I., Shin, I. (2010): "On the Optimal Level of Protection in DRM," Information Economics and Policy, Vol. 22(4), pp. 341-353.

Andres, A.A., (2006): "The relationship between copyright software protection and piracy: Evidence from Europe," European Journal of Law and Economics, Springer, vol. 21(1), pages 29-51, January.

Bae, S.H., and Choi, J.P. 2006. "A Model of Piracy," Information Economics and Policy, Vol. 18, pp. 303-320.

Banerjee, D.S. (2003): "Software Piracy: A Strategic Analysis and Policy Instruments," International Journal of Industrial Organization, Vol. 21(1), pp. 97-127.

Banerjee, D.S., Banerjee (Chaterjee) T., Raychaudhuri, A., (2008). "Optimal Enforcement and Anti-Copying Strategies to Counter Copyright Infringement," The Japanese Economic Review, Vol. 59, pp. 519-535.

Belleflamme, P. (2001): "Oligopolistic Competition, IT Use for Software Differentiation and the Productivity Paradox," International Journal of Industrial Organization, Vol. 19, pp. 227-248.

Belleflamme, P., and Peitz, M. (2012) "Digital Piracy: Theory," in: M. Peitz and J. Waldfogel (eds.), The Oxford Handbook of the Digital Economy, Oxford University Press (2012), pp. 489-530.

Belleflamme, P. and Peitz, M. (2014): "Digital Piracy: An Update.", ECORE Discussion Paper, No. 58.

Belleflamme, P., and Picard, P.M. (2007): "Piracy and Competition," Journal of Economics and Management Strategy, Vol. 16, pp. 351-383. 
Choi, P., Bae, S.H., and Jun, J. (2010): "Digital Piracy and Firms' Strategic Interactions: The Effects of Public Copy Protection and DRM Similarity," Information Economics and Policy, Vol. 22, pp. 354-364.

Harbaugh, R., and Khemka, R. (2010): "Does copyright enforcement encourage piracy?," Journal of Industrial Economics, Wiley Blackwell, Vol. 58(2), pp. 306323,06 .

Jain, S. (2008): "Digital Piracy: A Competitive Analysis," Marketing Science, Vol. 27, pp. 610-626.

King, S.P., and Lampe, R. (2003): "Network Externalities, Price Discrimination and Profitable Piracy," Information Economics and Policy, Vol. 15, pp. 271-290.

Kúnin, M. (2004): "Why do Software Manufacturers Tolerate Piracy in Transition and Less Developed Countries?" CERGE-EI Working Paper, No. 231.

Kúnin, M., and Žigić, K. (2006): "Strategic Trade Policy and Vertical Product Differentiation: Intra-industry Trade between Developed and Developing Countries," CERGE-EI Working Paper, No. 230.

Matsumura, T. and Ogawa, A., (2014): "Inefficient but robust public leadership," MPRA Paper No. 56539.

Minnitti, A., and Vergari, C. (2010): "Turning Piracy into Profits: A Theoretical Investigation," Information Economics and Policy, Vol. 22(4), pp. 379-390.

Peitz, M., (2004): "A Strategic Approach to Software Protection: Comment", Journal of Economics and Management Strategy 13, 371-374.

Peitz, M. and Waelbroeck, P. (2006):"Piracy of Digital Product: A Critical Review of the Theoretical Literature," Information Economics and Policy, Vol. 21(4), pp. 449-476. 
Poddar, S., Lu., Y., and Y. Zhang (2014): "Impact of Network Externality on Piracy: Revisited," Working Papers on IPR, Innovations and Piracy, University of Auckland, (Available at: http://works.bepress.com/sougata_poddar/4)

Scotchmer, S. (2004): Innovation and Incentives, The MIT Press.

Shaked, A., and Sutton, J. (1984): Natural Oligopolies and International Trade: An Introduction, Oxford University Press.

Shapiro, C. (2003): "Antitrust Limits to Patent Settlements," RAND Journal of Economics, Vol. 34, pp. 391-411.

Shy, O., and Thisse, J. (1999): "A Strategic Approach to Software Protection," Journal of Economics $\&$ Management Strategy, Vol. 8(2), pp. 163-190.

Stavins, J. (1995): "Model Entry and Exit in a Differentiated-Product Industry: The Personal Computer Market," The Review of Economics and Statistics, Vol. 77, pp. $571-584$.

Střelický, J and Žigić, K (2011): "Intellectual Property Rights Protection and Enforcement in a Software Duopoly," CERGE-EI Working Paper, No. 435 Sundararajan, A., (2004): "Managing Digital Piracy: Pricing and Protection," Information Systems Research, Vol. 15, pp. 287-308.

Sutton, J. (1991): Sunk Cost and Market Structure, The MIT Press.

Takeyama, L.N. (2009):"Copyright Enforcement and Product Quality Signaling in Markets for Computer Software," Information Economics and Policy, Vol. 21(4), pp. 291-296.

Tirole, J. (1988): The Theory of Industrial Organization, The MIT Press. 
Yoon, K. (2002): "The Optimal Level of Copyright Protection," Information Economics and Policy, Vol. 14, pp. 327-348.

Zhang, L. (2013): "Intellectual Property Strategy and the Long Tail: Evidence from the Recorded Music Industry", mimeo, Rotman School of Management, University of Toronto

Žigić, K. (2000): "Strategic Trade Policy, Intellectual Property Rights Protection, and North-South Trade," Journal of Development Economics, 2000, Vol. 61(1), pp. $27-60$.

Žigić, K., Střelický, J., and M. Kúnin. (2013). "The Interaction between Private and Public IPR Protection in a Software Market: A Positive and Normative Analysis", CERGE-EI Working Paper, No. 490.

Internet Sources: www.tomshardware.com, www.idg.com, www.zive.cz, www.ifpi.org, www.ria.com, www.pro-music.org. 


\begin{abstract}
Abstrakt
Analýza ekonomických dopadů softwarového pirátství se obvykle opírá o zjednodušující předpoklad, že produkt je nabízen jen jedním výrobcem. My ale namítáme, že popis charakteristik softwarového pirátství je realističtější v konkurenčním prostředí mezi více výrobci. Používání nelegálních verzí porušuje práva na ochranu duševního vlastnictví a pokud je porušení odhaleno, je trestáno. Pokud výrobce považuje úroveň pirátství za př́liš velkou, může se rozhodnout zavést vlastní ochranu proti kopírování. Zaměření naší analýzy je na interakci mezi veřejnou a soukromou ochranou ve dvou zvažovaných variantách struktury trhu. Ukážeme, že na rozdíl od monopolního trhu zde není konflikt zájmů mezi výrobci a regulátorem. Navíc oproti monopolnímu trhu neovlivňuje optimální ochrana kvalitu softwaru.
\end{abstract}




\section{Working Paper Series}

ISSN 1211-3298

Registration No. (Ministry of Culture): E 19443

Individual researchers, as well as the on-line and printed versions of the CERGE-EI Working Papers (including their dissemination) were supported from institutional support RVO 67985998 from Economics Institute of the ASCR, v. v. i.

Specific research support and/or other grants the researchers/publications benefited from are acknowledged at the beginning of the Paper.

(c) Krešimir Žigić, Jiří Střelický, and Michael Kúnin, 2015

All rights reserved. No part of this publication may be reproduced, stored in a retrieval system or transmitted in any form or by any means, electronic, mechanical or photocopying, recording, or otherwise without the prior permission of the publisher.

Published by

Charles University in Prague, Center for Economic Research and Graduate Education (CERGE) and

Economics Institute of the ASCR, v. v. i. (EI)

CERGE-El, Politických vězňů 7, 11121 Prague 1, tel.: +420 224005 153, Czech Republic.

Printed by CERGE-EI, Prague

Subscription: CERGE-EI homepage: http://www.cerge-ei.cz

Phone: + 420224005153

Email: office@cerge-ei.cz

Web: http://www.cerge-ei.cz

Editor: Marek Kapička

The paper is available online at http://www.cerge-ei.cz/publications/working_papers/.

ISBN 978-80-7343-358-1 (Univerzita Karlova v Praze, Centrum pro ekonomický výzkum a doktorské studium)

ISBN 978-80-7344-353-5 (Národohospodářský ústav AV ČR, v. v. i.) 
CERGE-EI

P.O.BOX 882

Politických vězňů 7

11121 Praha 1

Czech Republic http://www.cerge-ei.cz 